\title{
A conservação do estandarte da Faculdade de Medicina da Universidade de São Paulo'
}

\author{
Teresa Cristina Toledo de Paula \\ Divisão de Acervo e Curadoria \\ do Museu Paulista da USP \\ Luciana Coutinho da Silveira \\ Conservadora de têxteis autônoma
}

RESUMO: Este texto descreve, com o apoio de desenhos e imagens, os diferentes aspectos considerados no desenvolvimento do trabalho de conservação e restauração de um estandarte de tecido pertencente à Faculdade de Medicina da Universidade de São Paulo, Brasil, realizado entre setembro de 2001 e julho de 2002 no Setor de Têxteis do Museu Paulista da USP. O estandarte, criado em 1918 para representar a Escola de Medicina em desfiles e celebrações públicas, foi encomendado ao pintor Oscar Pereira da Silva e traz os principais símbolos atribuídos à medicina. Confeccionado em tecido de seda verde (cor atribuída à medicina), entretanto, desde muito tempo teve sua cor alterada para amarelo ouro e, como um estandarte cor de ouro, tornou-se o símbolo da escola nas últimas décadas. Este artigo descreve em detalhes o processo de tomada de decisão e o tratamento de conservação realizado. PALAVRAS-CHAVE: Tecidos no Brasil. Têxtil. Conservação de têxteis. Cor.

ABSTRACT: The paper presents different aspects considered in the conservation treatment process of a Medical Science School banner, belonging to the University of São Paulo, Brazil. The banner, created in 1918 to represent the Medical School in parades and public celebrations, was commissioned to Oscar Pereira da Silva, a famous Brazilian painter and it It features the main symbols of the medical sciences. The banner was conceived and made with green silk as green was (still is) the colour attributed to the medical sciences in Brazil. However, it has turned into a gold colour some considerable time ago, and it was as a gold banner that it became the symbol of the School in the last decades. Books and documents have been published showing the golden symbol. This paper seeks to detail the conservation treatment carried out and the decision-making process involved in the work. KEYWORDS: Textiles in Brazil. Fabrics. Textile Conservation. Colour.

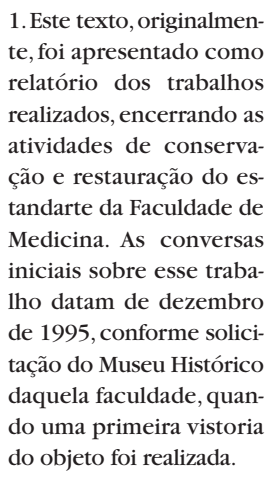

do objeto foi realizada. 
2.Além das autoras, o trabalho contou com a participação do assistente Rafael Celidônio Rodrigues, especialista em $\mathrm{Mu}$ seologia.
Este texto descreve, com o apoio de desenhos e imagens, o trabalho de conservação e restauração de um estandarte de tecido pertencente à Faculdade de Medicina da Universidade de São Paulo, Brasil, realizado entre setembro de 2001 e julho de 2002 no Setor de Têxteis do Museu Paulista da USP (Figura 1$)^{2}$. Nossa opção por publicá-lo neste formato, quase um roteiro da intervenção, foi didática, já que a atividade de conservação e restauração de têxteis no Brasil ainda é pouco difundida e sua especificidade, metodologia e prática merecem ser melhor conhecidas.

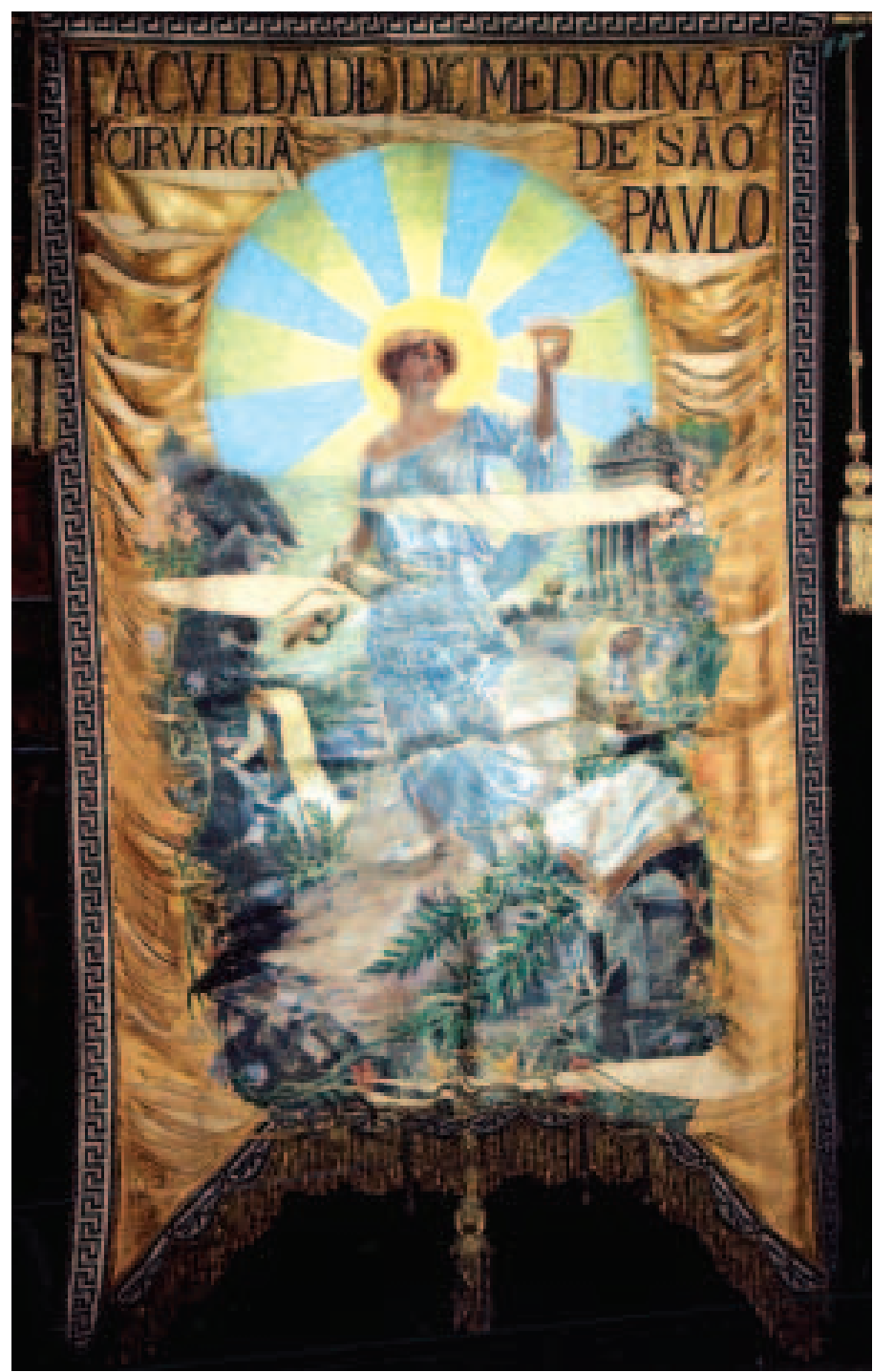

Figura 1 - Estandarte em exposição na diretoria da Faculdade de Medicina. 
trabalho de intervenção precisou considerar, entre outras coisas, a mudança de cor do estandarte. Seu verde original, cor atribuída à medicina, transformou-se com o tempo em amarelo-ouro lacredita-se que a mudança foi causada pelo pigmento azul presente no corante verde) contrariando, inclusive, as informações dos curadores que sempre o consideraram amarelo já que dispunham de documentação, textos e recibos de época mencionando a confecção do estandarte sobre um tecido de seda amarela:

A diretoria do Centro Acadêmico Oswaldo Cruz, eleita a 5 de outubro de 1914, sob a presidência de Jaime Candelária, elaborou novos estatutos para o Centro, entre eles a organização do livro de ouro para confecção do ESTANDARTE DA FACULDADE DE MEDICINA. Foi dirigido convite a Ramos de Azevedo que se prontificou a elaborar o plano do estandarte, pois sendo destinado à faculdade necessitava da aprovação da Congregação. Quando reeleito para presidente, no biênio 1916-1917, Ernesto de Souza Campos teve como um dos primeiros atos a confecção do estandarte, cujo livro de ouro alcançou 2:650\$000. Encarregou-se da obra o renomado pintor Oscar Pereira da Silva, que compôs e pintou o quadro sobre seda amarela. A parte de marcenaria foi entregue ao Liceu de Artes e Ofícios. ${ }^{3}$

Em momento algum foi cogitada pelos conservadores responsáveis, a hipótese de alterar a cor do tecido original, pois procedimentos dessa natureza são considerados inaceitáveis. Mas era fato que a cor original do estandarte, a cor símbolo, tinha sido outra no início, questão essa que precisava ser abordada. A opção encontrada pelos conservadores e submetida à aprovação dos curadores foi a de trabalhar com a cor verde, em tons diversos, nos três tecidos novos que seriam introduzidos durante o trabalho de conservação e restauração. $\bigcirc$ efeito visual criado com esse procedimento foi considerado satisfatório, deixando o estandarte mais próximo da cor verde do que da amarela.

Outra questão discutida foi a de que o estandarte, após a intervenção, não poderia mais ser exposto na posição vertical na sala do diretor da faculdade, onde sempre esteve, já que mesmo conservado, continuaria muito frágil e exposto à ação da gravidade, que a longo prazo novamente the causaria danos. Decidiuse então expô-lo inclinado sobre um suporte em uma vitrina especialmente projetada para recebêto.

Características do objeto

O estandarte da Faculdade de Medicina da USP, de 1916, foi criado por Guilherme Bastos Milward e desenhado por Oscar Pereira da Silva. Medindo aproximadamente $160 \times 115 \mathrm{~cm}$, é composto por vários tecidos superpostos (Figura 2). O tecido do anverso, provavelmente seda e algodão, é pintado $190 \%$ da área) e bordado com fios metálicos em sua parte superior. Nas laterais e extremidade superior, encontram-se bordados de fios metálicos, de um só padrão, repetido por toda a extensão mencionada. Da extremidade inferior, descem 


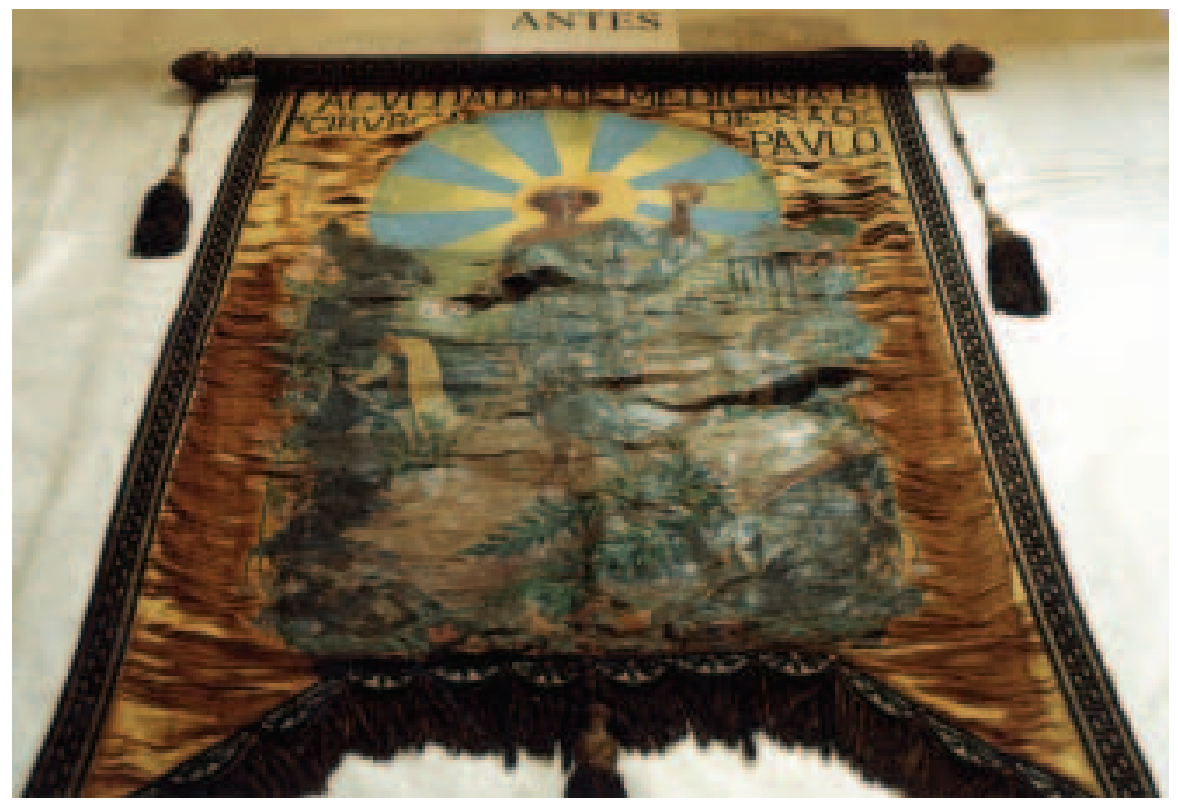

Figura 2 - Vista geral do estandarte - anverso - imagem anterior à restauração.

franjas de fios metálicos largos e, ao centro, desce um pingente do mesmo material. Internamente, um tecido celulósico (algodão) sustenta toda a estrutura. O verso apresenta um outro tecido na cor verde provavelmente de seda e algodão. Toda a estrutura se encontra presa a um bastão de madeira dourado, donde, em cada lateral, desce um pingente (borla) de fios metálicos.

O estado geral de conservação do estandarte era ruim. Todos os problemas verificados no laudo de 1995 encontravam-se potencializados. As distorções, dobras e vincos em toda a sua extensão foram agravados sensivelmente. Havia roturas horizontais em ambas as áreas laterais à região com pintura. Esta, por sua vez, também apresentava grandes roturas e perdas localizadas de pigmento em toda a sua extensão. Os elementos de metal estavam escurecidos provavelmente por causa da oxidação. Vários dos problemas demonstrados pelo objeto, senão todos, originaram-se, acreditamos, da ação do tempo, do peso da pintura sobre o tecido e do peso excessivo do pingente metálico inferior central.

Neste texto estarão descritas e detalhadas as principais etapas do trabalho.

Descrição das atividades desenvolvidas

O estandarte foi transportado para o Museu Paulista, em um veículo da instituição, dobrado, sobre cilindro, e sustentado por placa de Ethafoam e tecido. 
1. A primeira atividade foi a fotografação exaustiva antes da restauração e a marcação em desenhos de detalhes, marcas, costuras anteriores, partes faltantes, etc.

2. Seguiu-se, então, um pré-tratamento por limpeza mecânica superficial, do anverso, com aspirador de baixa sucção. Paralelamente foram realizados testes preliminares com os seguintes adesivos sobre amostras de tecido semelhante ao encontrado no estandarte: Lascaux 360 HV"; Beva Gel"; Jade R"; Jade 71 1"; Roplex N580"; todos a 100\% e, em seguida, a 50\% diluído em água destilada.

3. A limpeza da superfície da área com pintura foi realizada com uso de enzima para remoção das sujidades aderidas.

4. $\bigcirc$ próximo passo foi o desmembramento das diversas camadas de tecido, galão e franja e a limpeza mecânica e superficial com aspirador de baixa sucção do tecido do verso.

5. Após realizarmos testes com o uso de diversos solventes/quelante foi feita a limpeza mecânica dos fios metálicos dos galões e das partes metálicas com solvente orgânico - pinhas de acabamento do suporte de madeira e franja.

6. Em seguida foram removidos os reparos anteriores na área de tecido de seda e a remoção parcial do galão das bordas. As áreas superiores não puderam ser removidas por estarem costuradas ao suporte interno.

7. As atividades seguintes foram a remoção do tecido do verso do estandarte, a preparação de quelante para "limpeza" da corrosão nos fios metálicos e a confecção da tenda de umidificação e do suporte para planificação.

8. Todos os elementos metálicos foram limpos com EDTA com $\mathrm{pH} 7^{4}$, etanol e pincel de fibras de vidro.

9. Seguiram-se a limpeza profunda do forro interno, por contato, com uso de etanol e água desmineralizada e a planificação e remoção dos seus vincos com utilização de pesos de vidro.

10. Vencida essa etapa foram removidos os reparos anteriores por costura, na área da pintura e área superior do tecido de cetim verde, e iniciada a planificação da pintura para remoção e minimização das distorções causadas pela sua ondulação.

11 . Após a constatação de que o estandarte, originalmente, era verde, teve início a etapa de escolha e tingimento dos novos tecidos que seriam introduzidos como suporte, bem como o teste de adesivos para escolha final daqueles que seriam usados tanto no tecido de suporte do verso quanto do anverso.
4. O EDTA concentrado em solução de $\mathrm{pH} 7$ foi preparado segundo indicação do Dr.Marco Ferretti, cientista senior em metais do CNR/Istituto per le Tecnologie Applicate ai Beni Culturali, Roma. 
12. A produção e tingimento de amostras (crepeline de seda e tule de poliamida) em diferentes tons para escolha dos mais compatíveis vieram acompanhados do tingimento final nos dois tecidos de suporte, após escolha dos tons ideais (crepeline de seda e tule de poliamida).

13. Paralelamente foi realizada a fixação dos fios metálicos soltos na área superior dos galões laterais.

14. A pintura em desprendimento foi fixada com Klucel $G^{\prime \prime}$.

15. Ao tecido que foi introduzido sob a pintura, microfibra de poliéster, aplicou-se o adesivo Rhoplex $N 580^{\circledR}$; já ao tecido que foi introduzido sobre o estandarte, crepeline de seda, foi aplicado o adesivo Lascaux $360 \mathrm{HV}^{\circledR}$.

16. Iniciou-se, então, o alinhamento e relaxamento, um a um dos fios soltos na área adjacente à pintura.

17. Em seguida foi introduzida, sob o estandarte, a microfibra de poliéster. A adesão foi feita pela reativação térmica e química do adesivo Rhoplex $N 58{ }^{\circledR}$ previamente aplicado à microfibra.

18. Os fios de seda da trama, na área das letras, foram fixados por costura.

19. A próxima etapa foi a aplicação do crepeline de seda sobre o estandarte (excetuando-se a área da pintura) pela reativação térmica do adesivo Lascaux $360 \mathrm{HV}{ }^{\circledR}$ previamente aplicado ao crepeline. $\bigcirc$ crepeline sobre as letras bordadas foi removido.

20. Foram feitas várias linhas de costura para dar maior segurança e sustentação às três camadas de tecido agora juntas (crepeline + estandarte + microfibra): margens da pintura, área com letras e nas aberturas da pintura.

21. A seguir usou-se o tule tingido sobre todo o estandarte costurado.

22. $\bigcirc$ cetim verde do verso do estandarte foi recolocado sob as outras camadas após receber reparos e sustentação na parte inferior (microfibra + crepeline + costura) e uma faixa de extensão na extremidade superior (microfibra + crepeline + costura).

23. A borla inferior central ganhou um tecido de tule protegendo as franjas. 


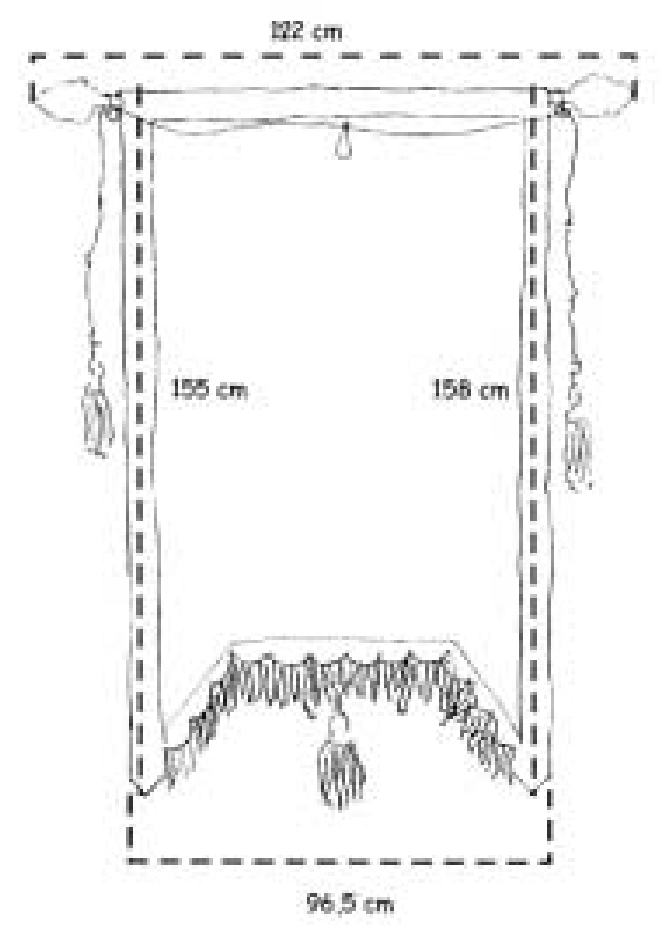

sobreposiçðo dos tecidas

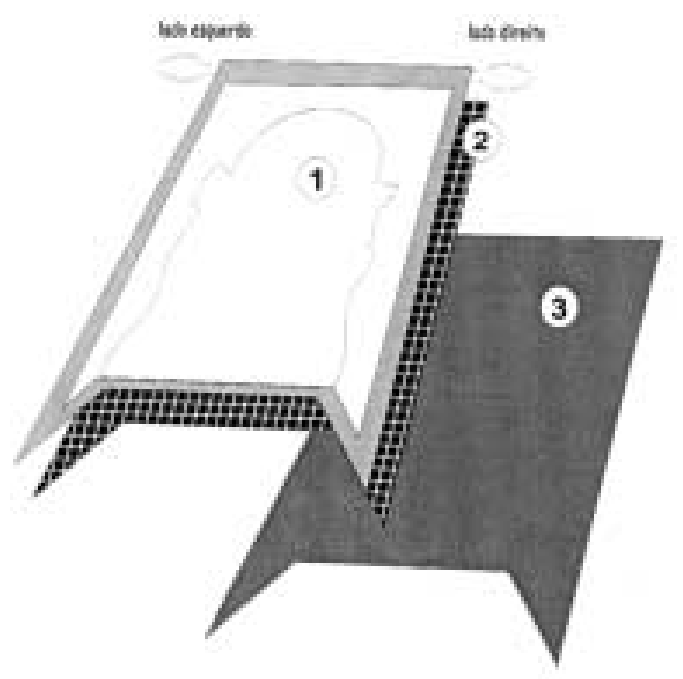

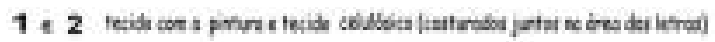

3 cetinuete 


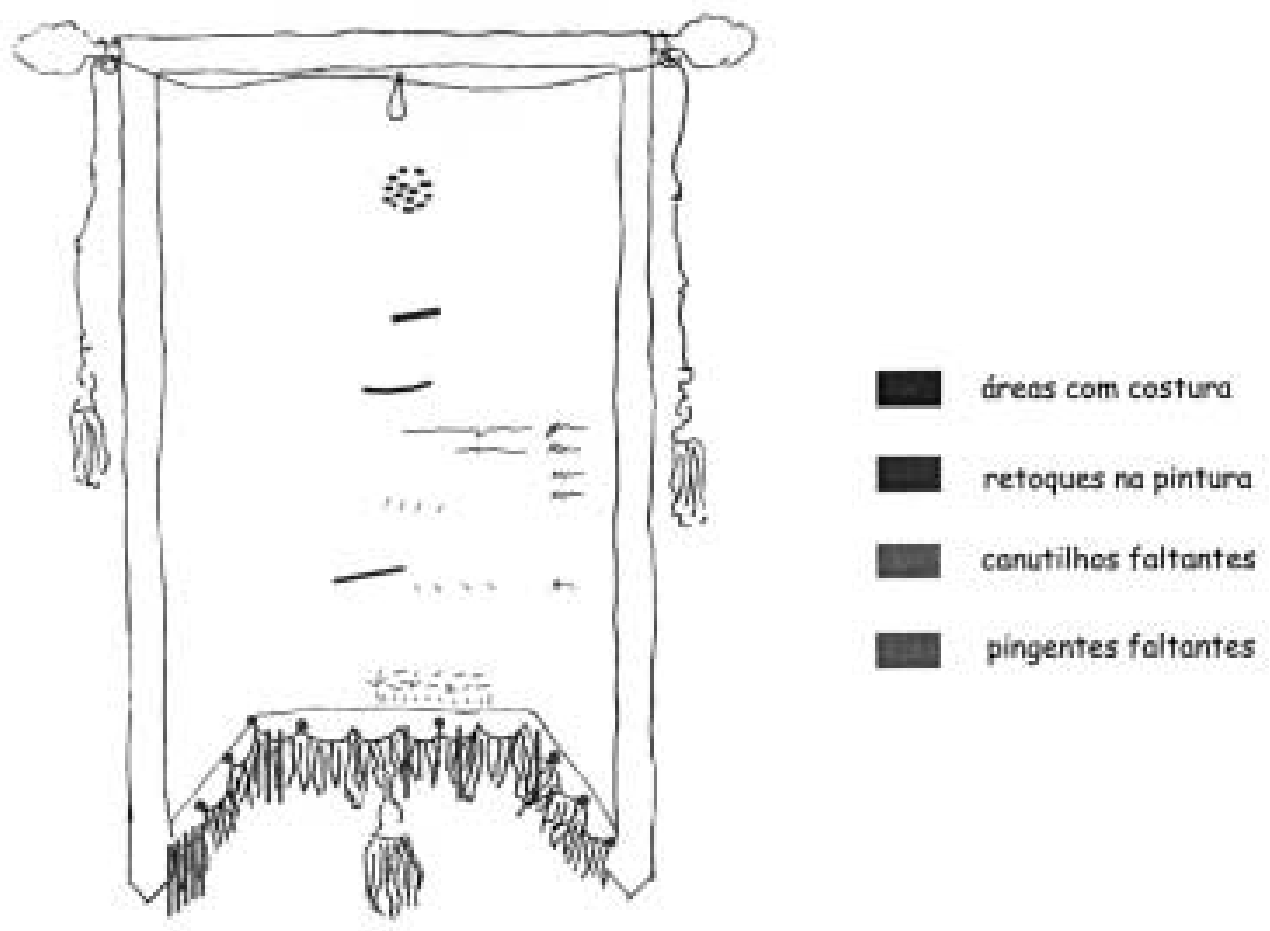

tecidos introduzidos como superte:

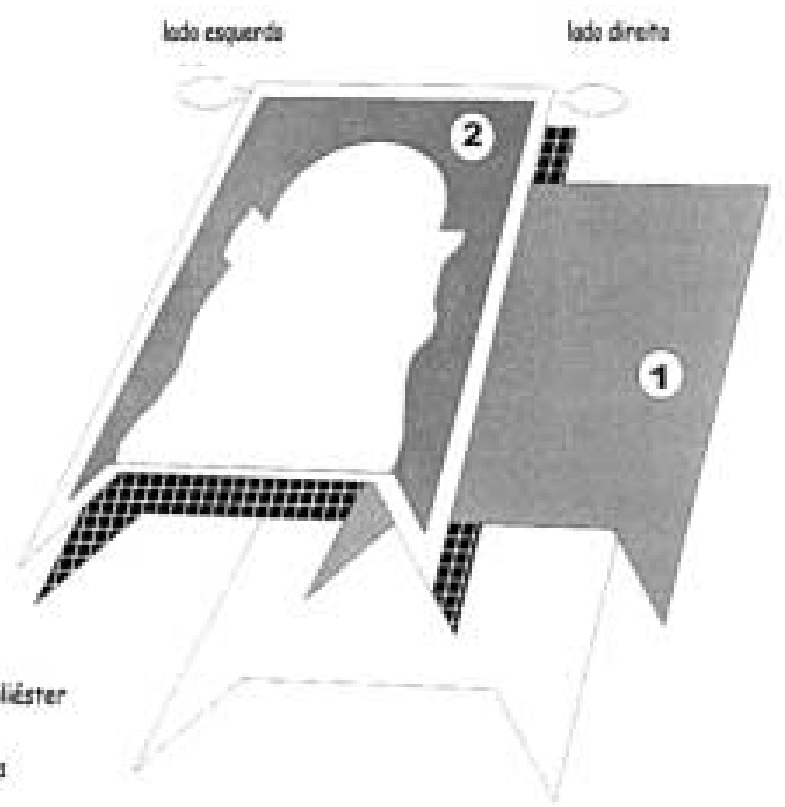



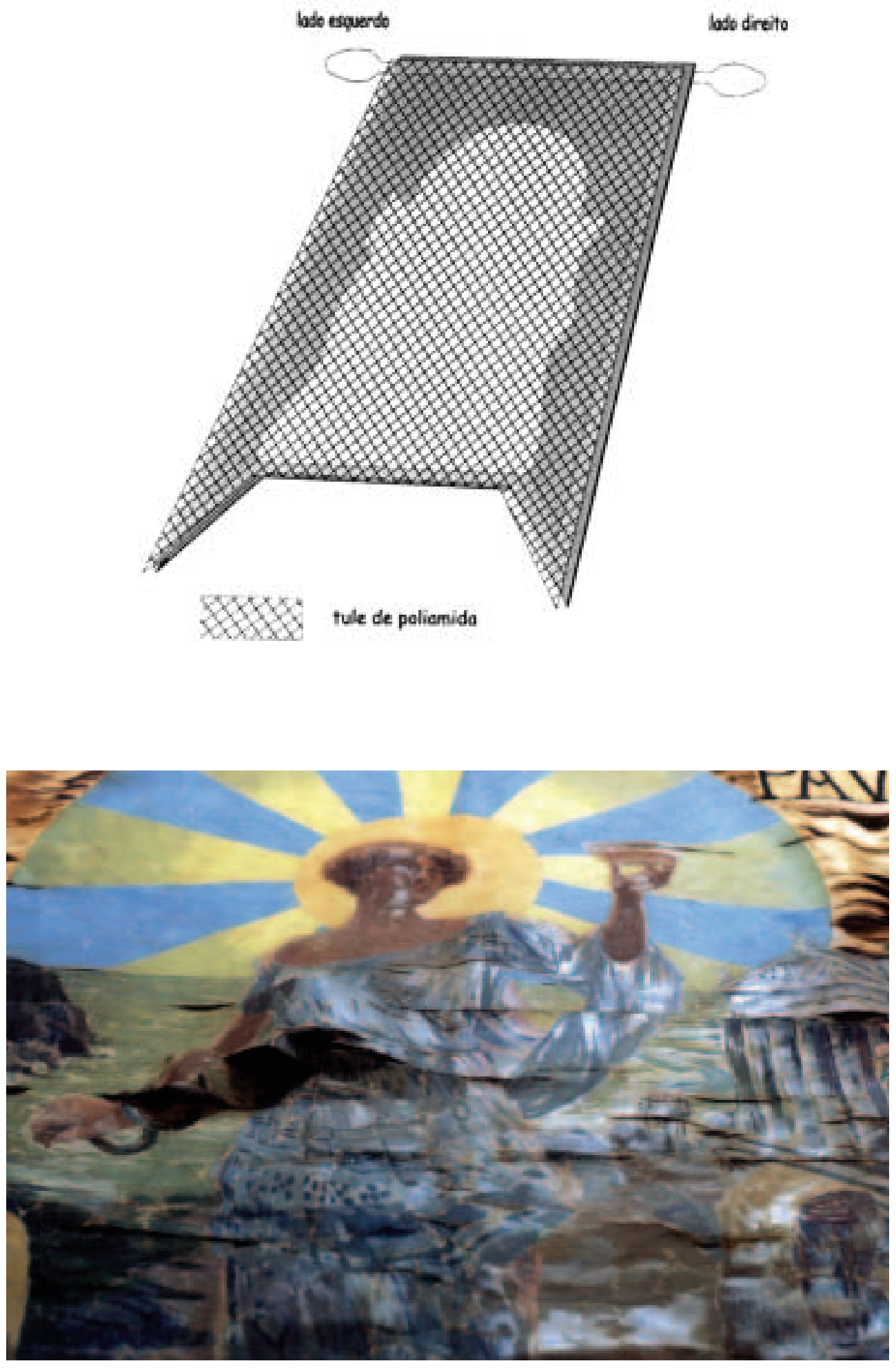

Figura 3 - Rasgos e ondulações na área central da pintura. 


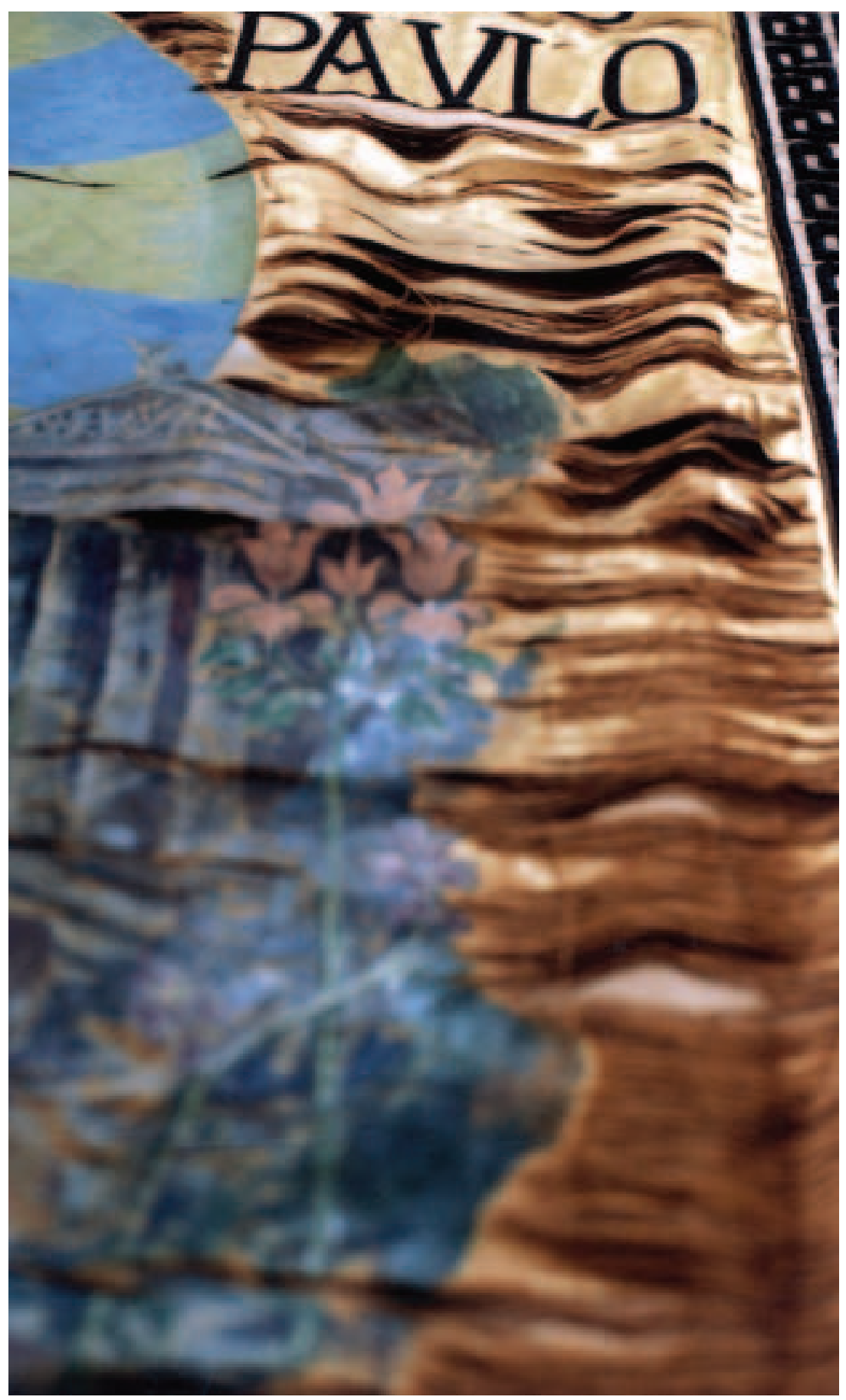

Figura 4 - Rompimento da tecedura, rasgos e ondulações (detalhe). 


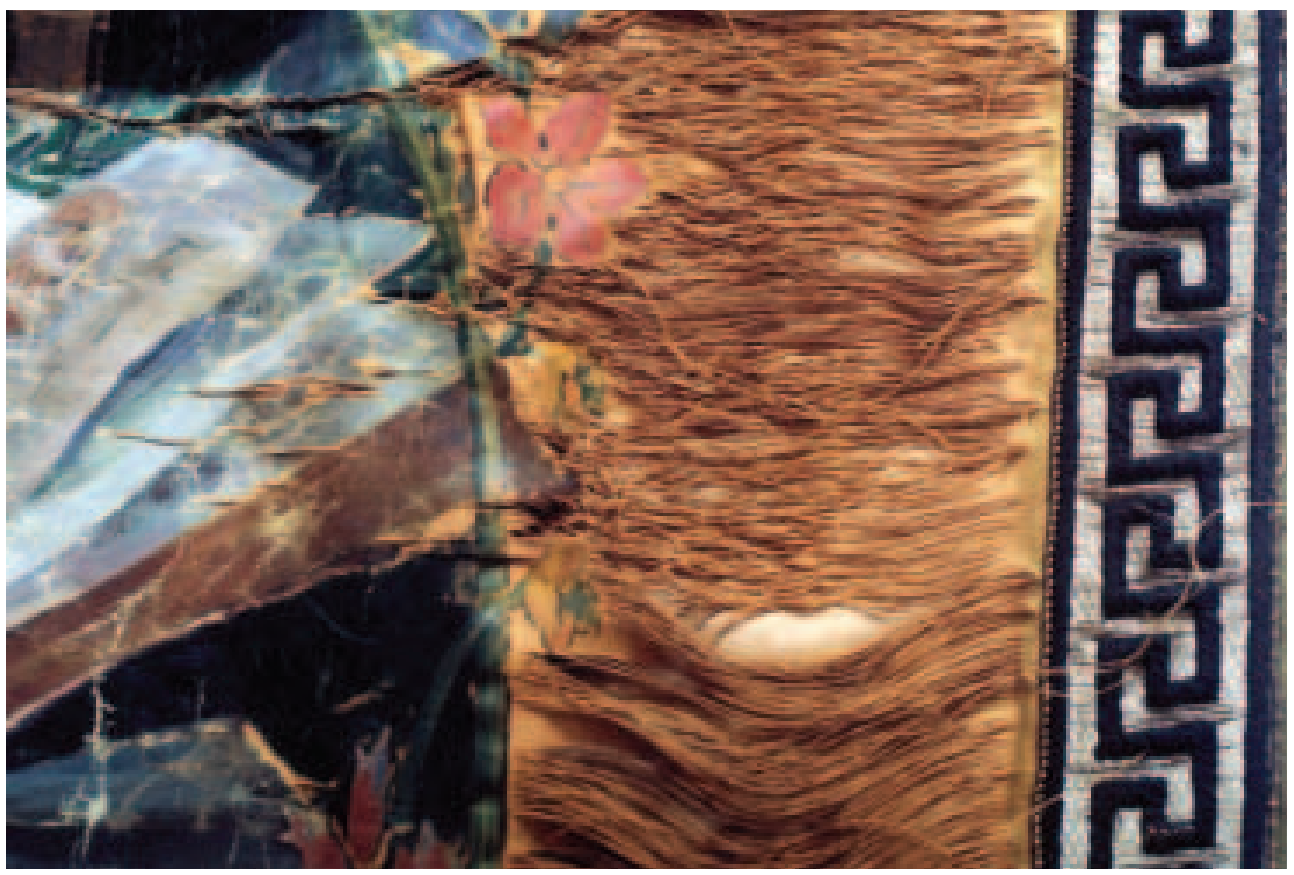

Figura 5 - Rompimento da tecedura, lado direito (detalhe).

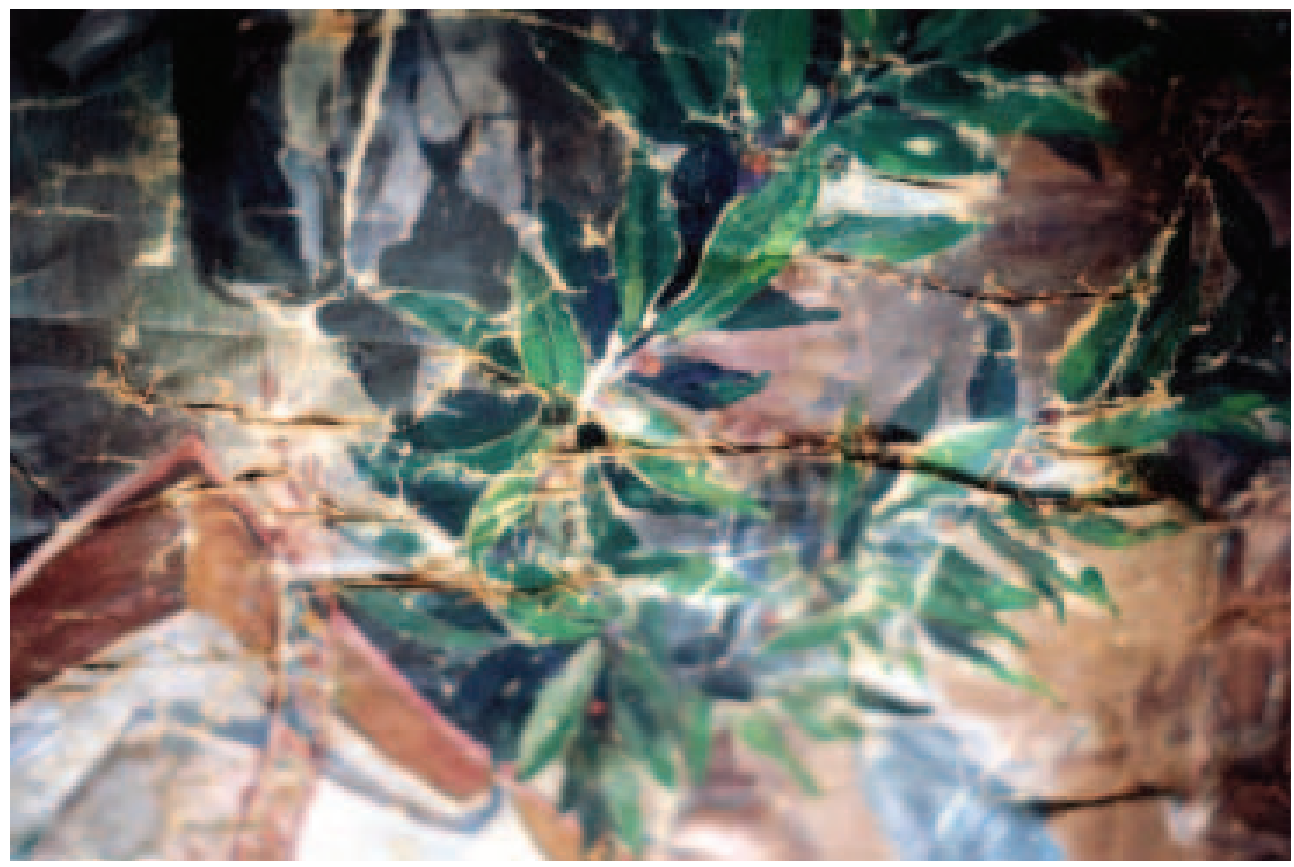

Figura 6 - Detalhe de intervenção anterior sobre a pintura (costuras). 


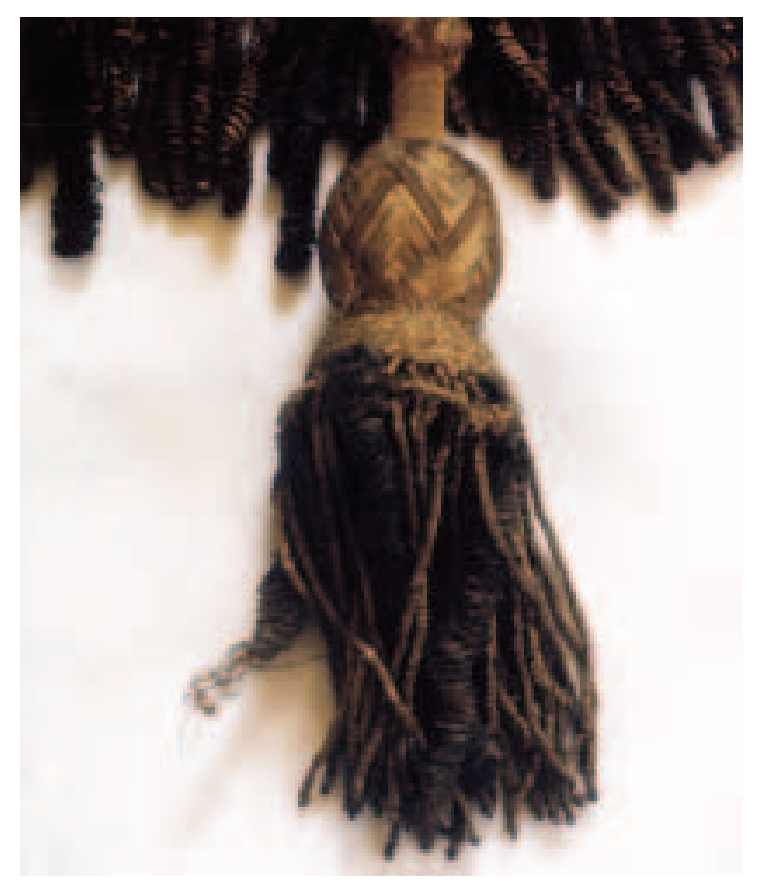

Figura 7 - Estado de conservação da borla inferior.

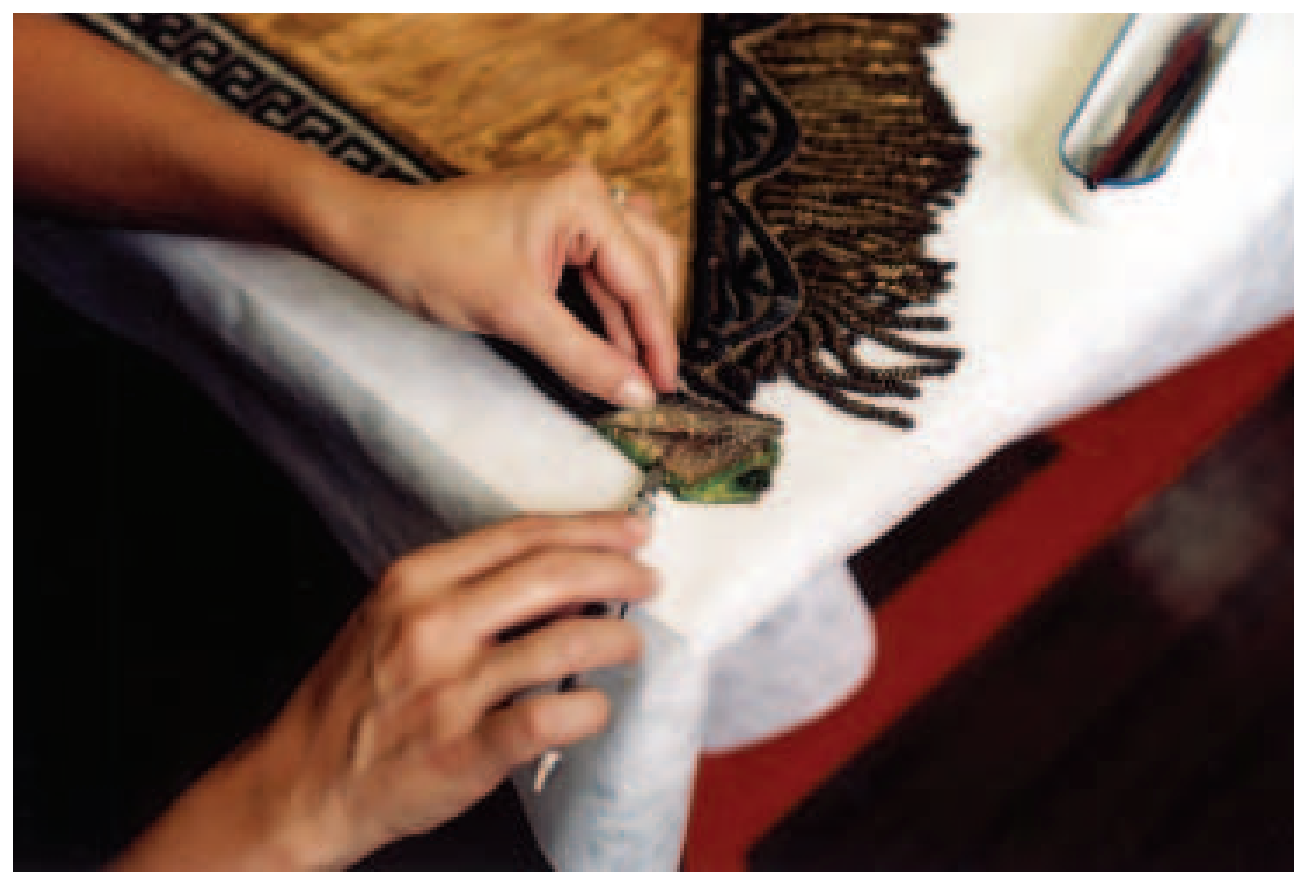

Figura 8 - Processo de abertura e separação das partes do estandarte. Nota-se a cor verde original do tecido não exposto à luz. 


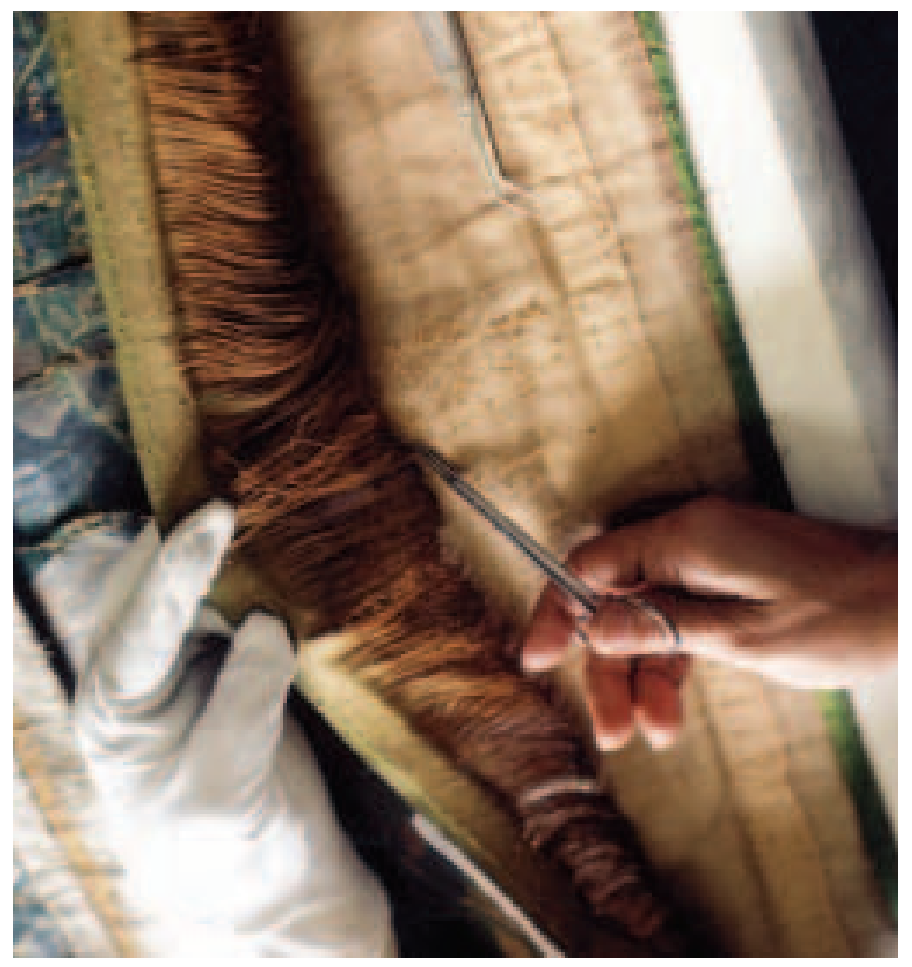

Figura 9 - Remoção das intervenções anteriores (costuras), na lateral esquerda.

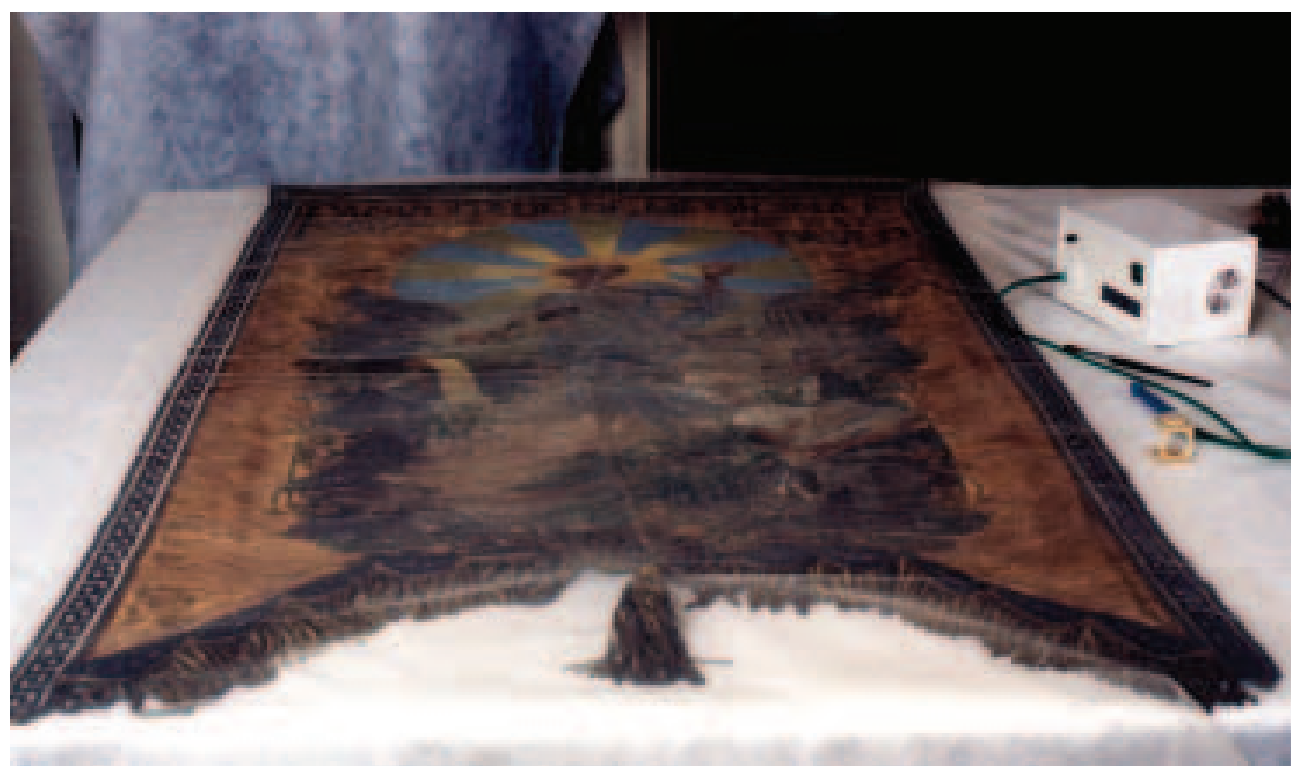

Figura 10 - Higienização com aspirador de baixa sucção. Nota-se o tule colocado sobre o objeto para evitar o deslocamento de fios e/ou partes em desprendimento. 


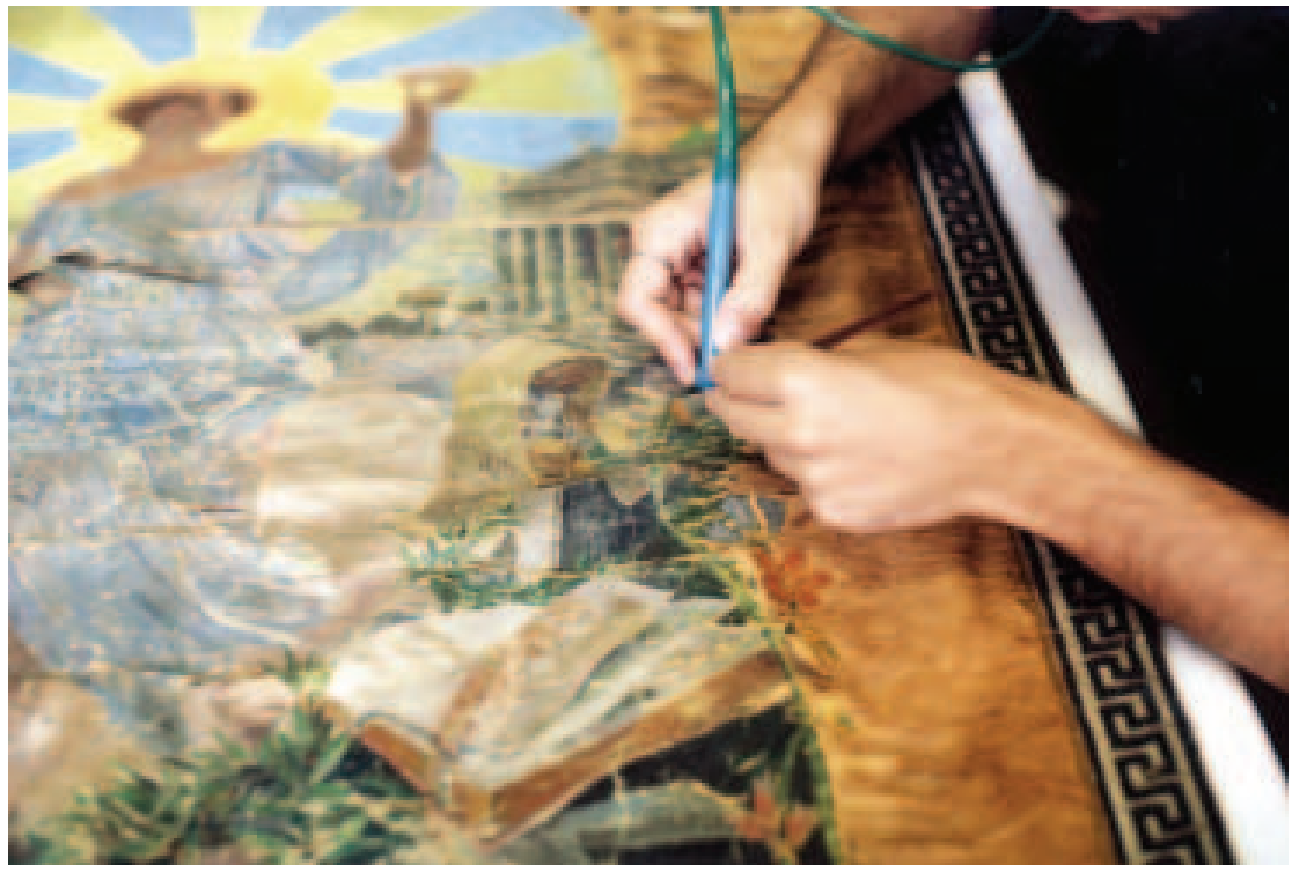

Figura 11 - Higienização, fio a fio, com aspirador de baixa sucção.

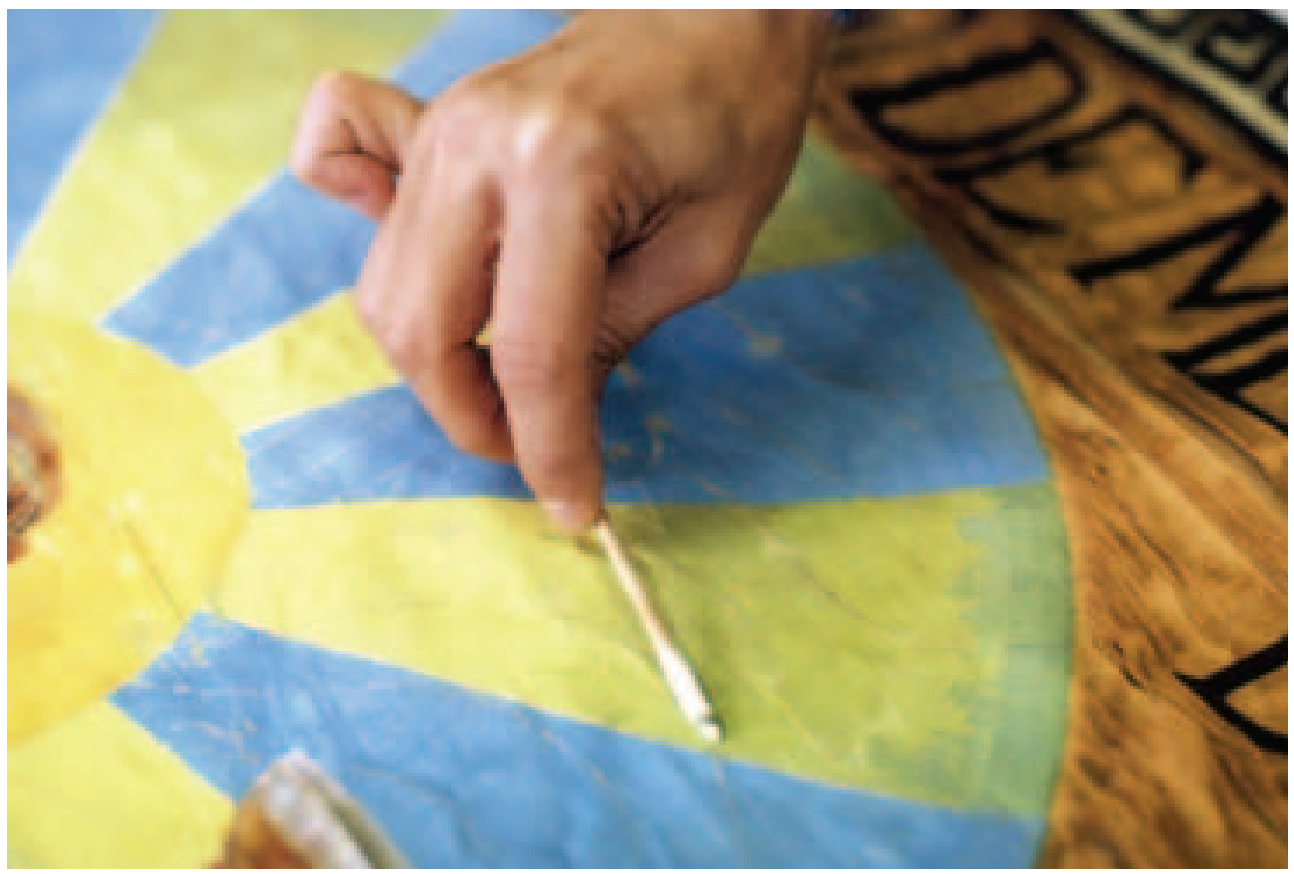

Figura 12 - Remoção mecânica da sujidade com enzima. 


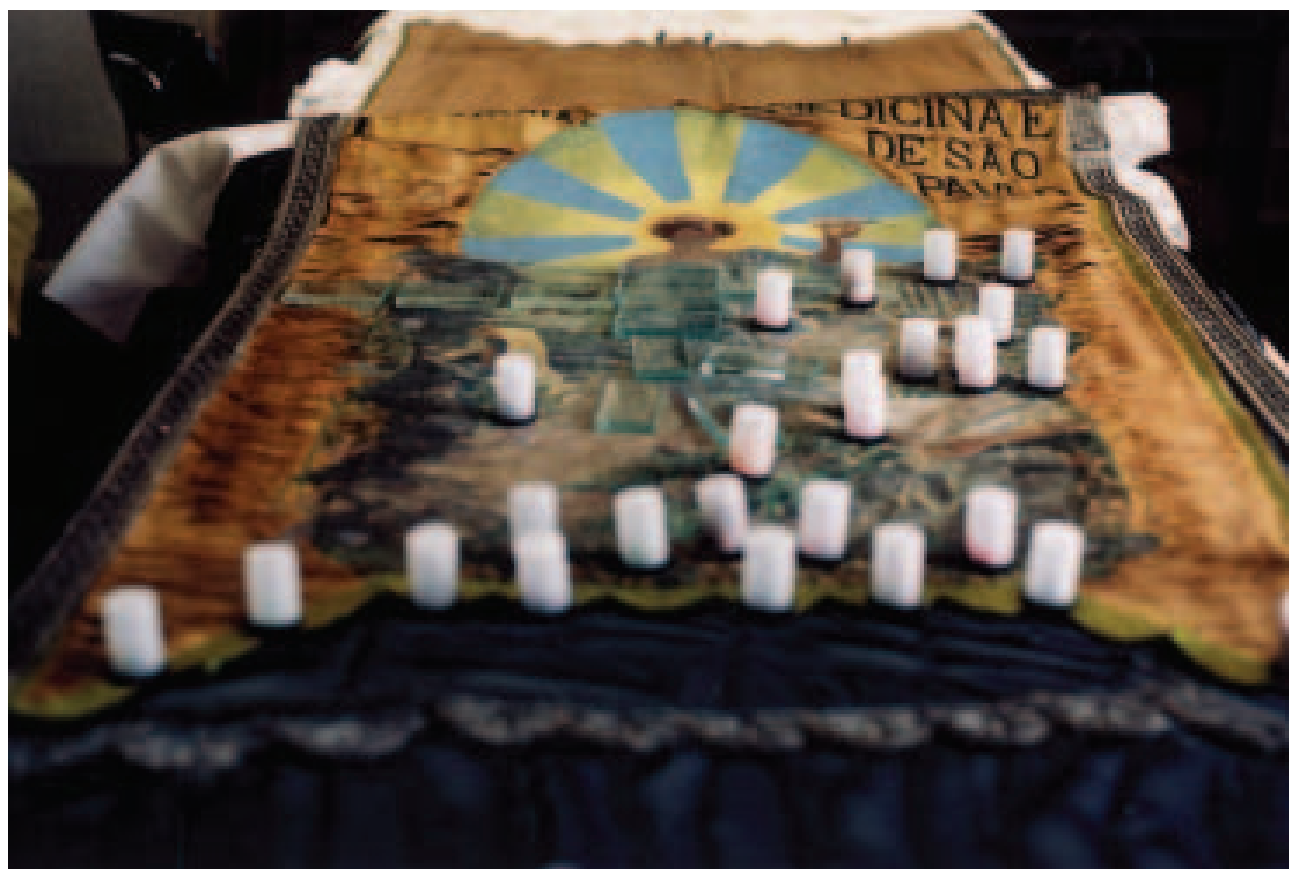

Figura 13 - Início do processo de planificação com a utilização de pesos diferenciados.

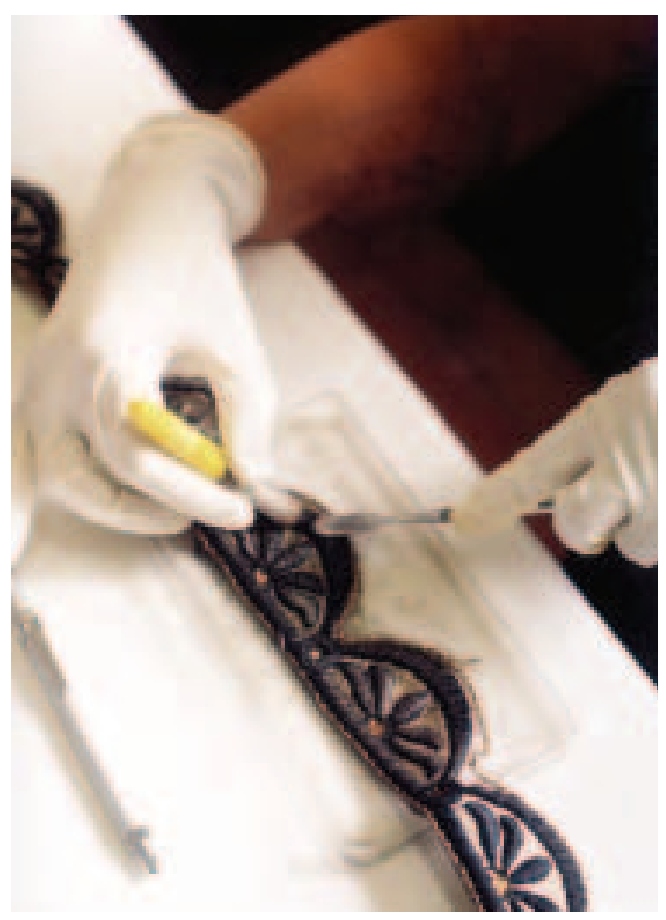

Figura 14 - Limpeza dos fios metálicos do galão. 


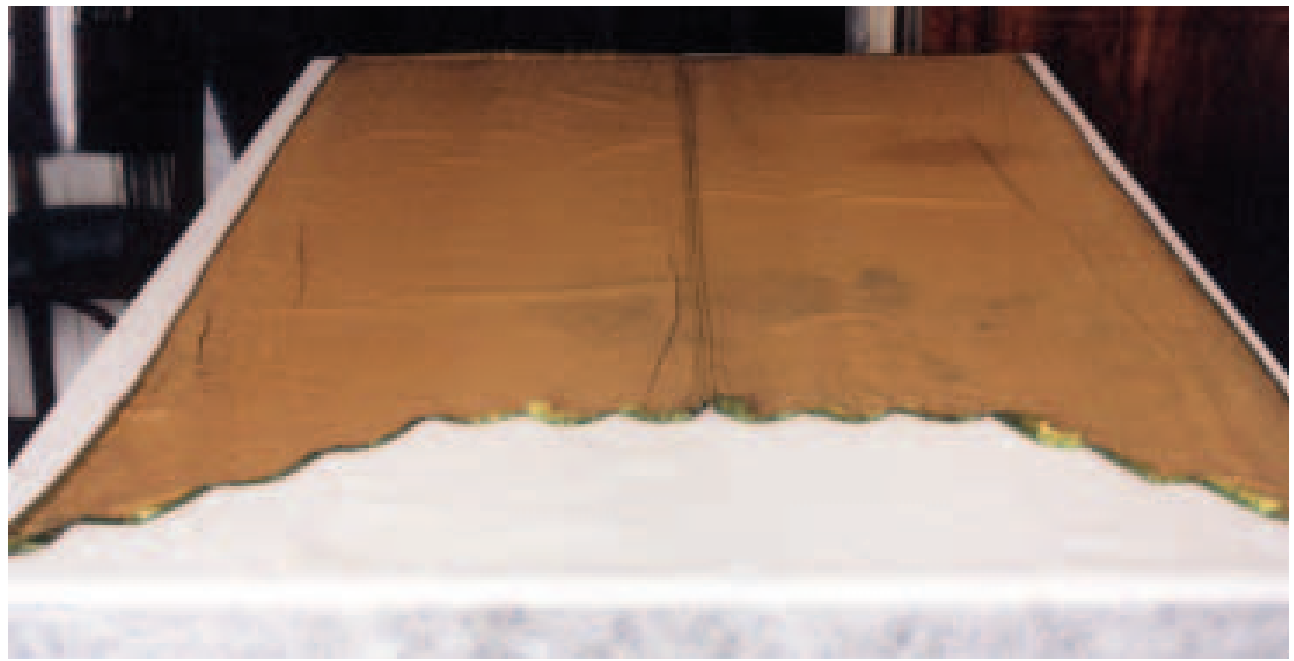

Figura 15 - Parte interna do cetim verde.

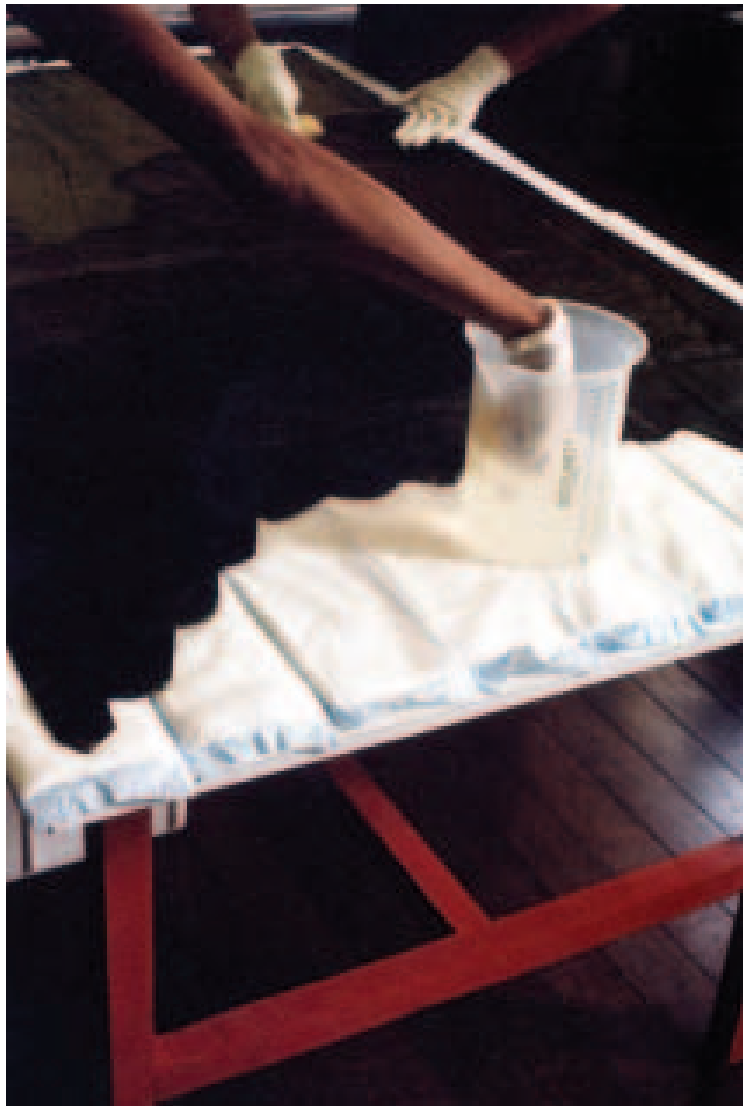

Figura 16 - Limpeza do cetim verde. 


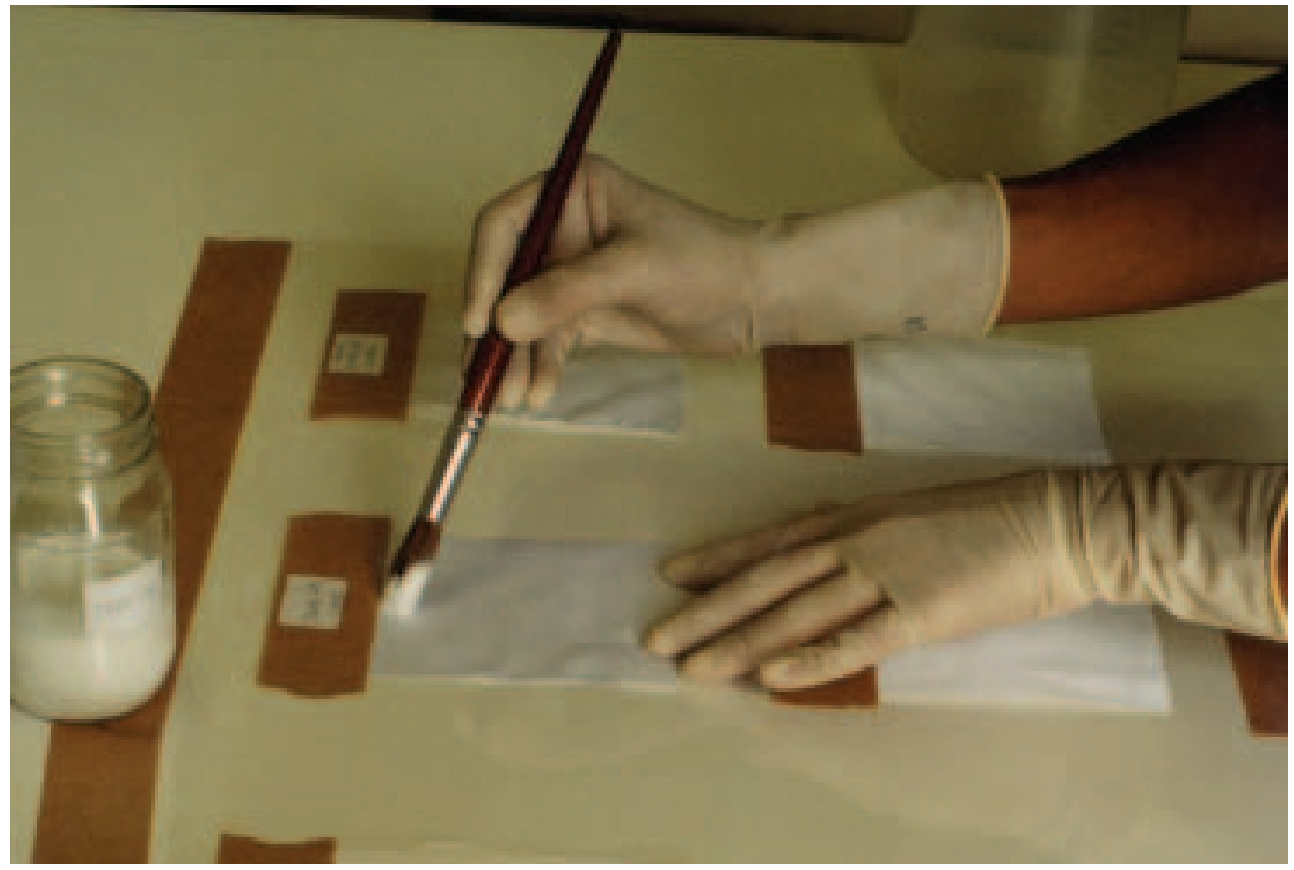

Figura 17 - Realização de testes com os diversos adesivos a serem utilizados.

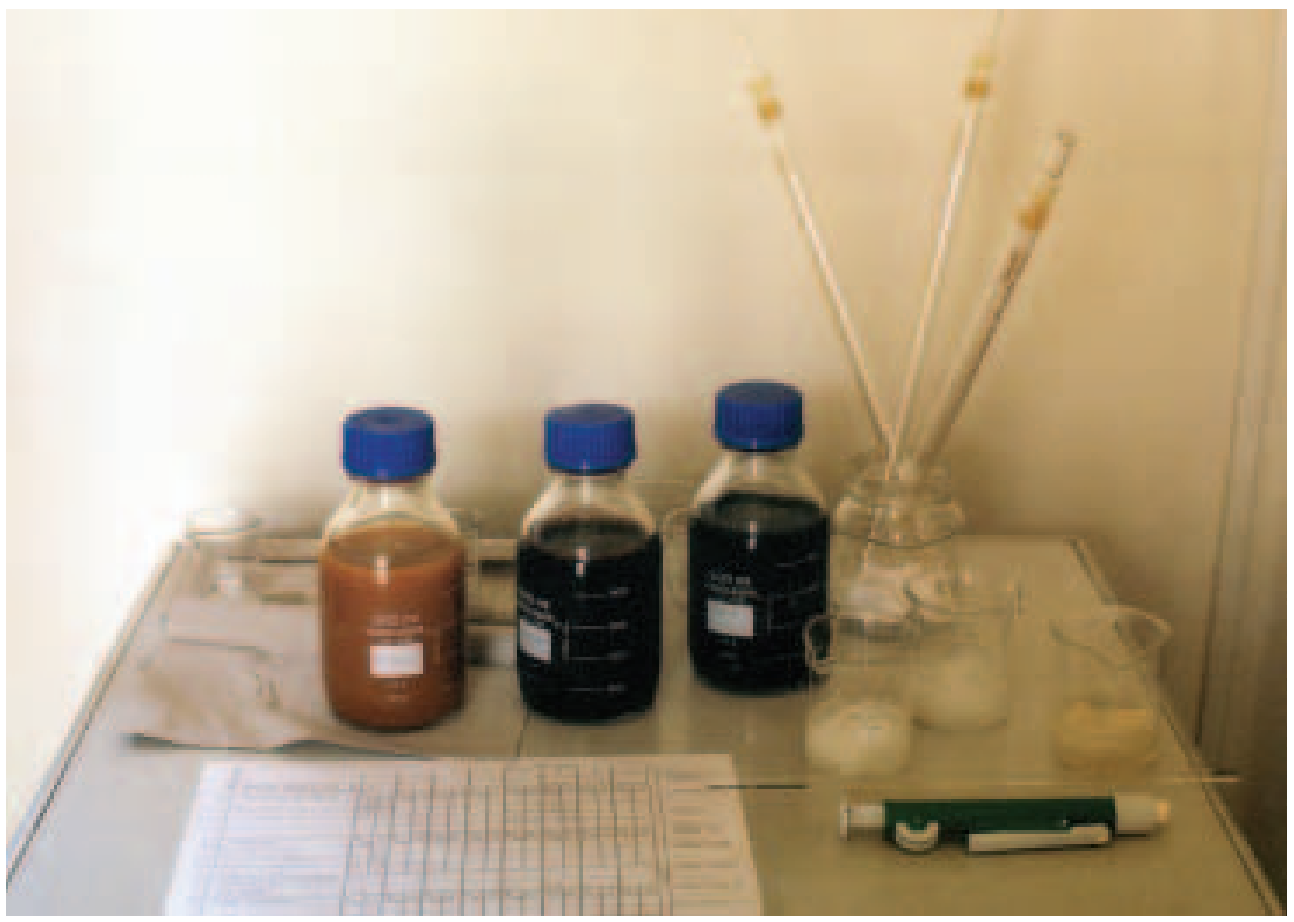

Figura 18 - Preparação dos corantes para o tingimento dos novos tecidos introduzidos no estandarte. 


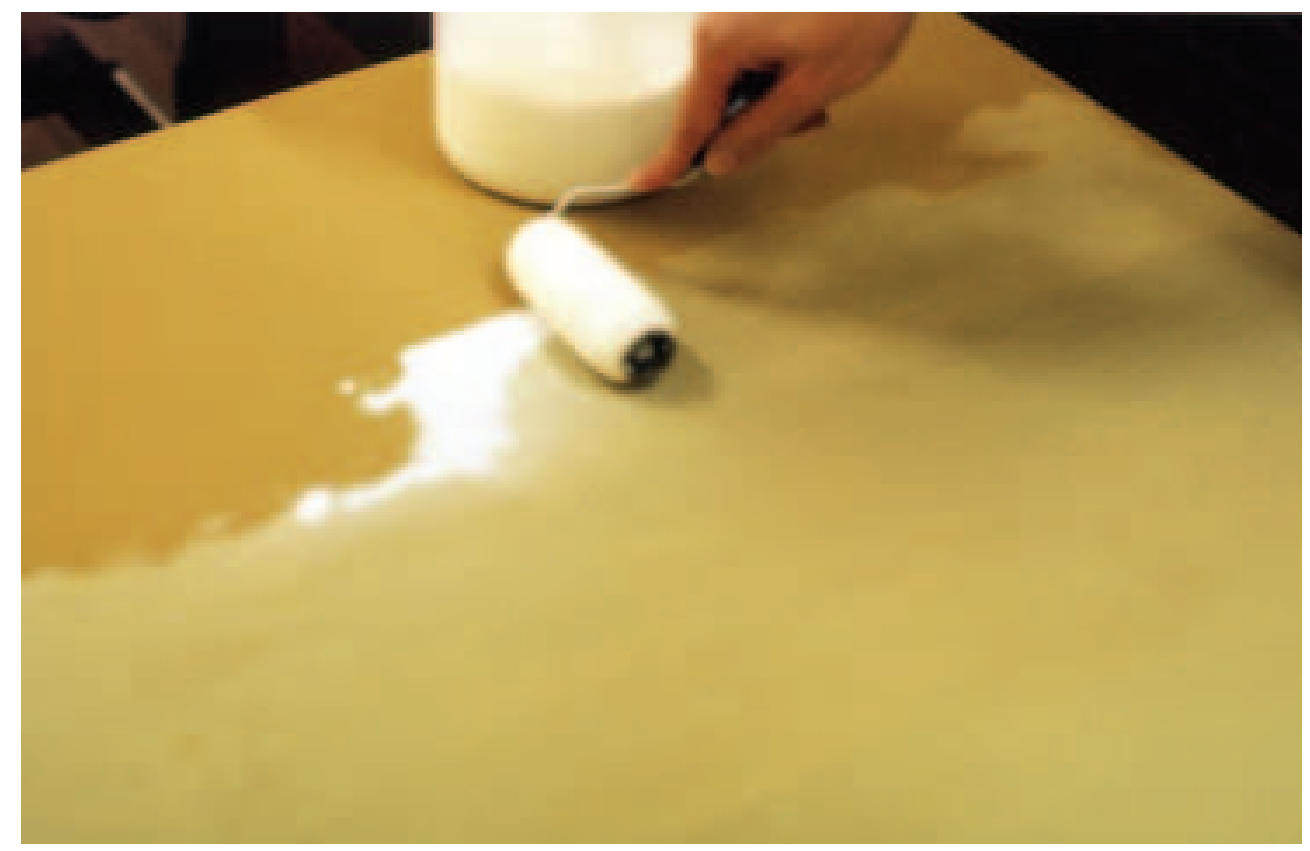

Figura 19 - Aplicação de adesivo sobre o tecido de microfibra de poliéster.

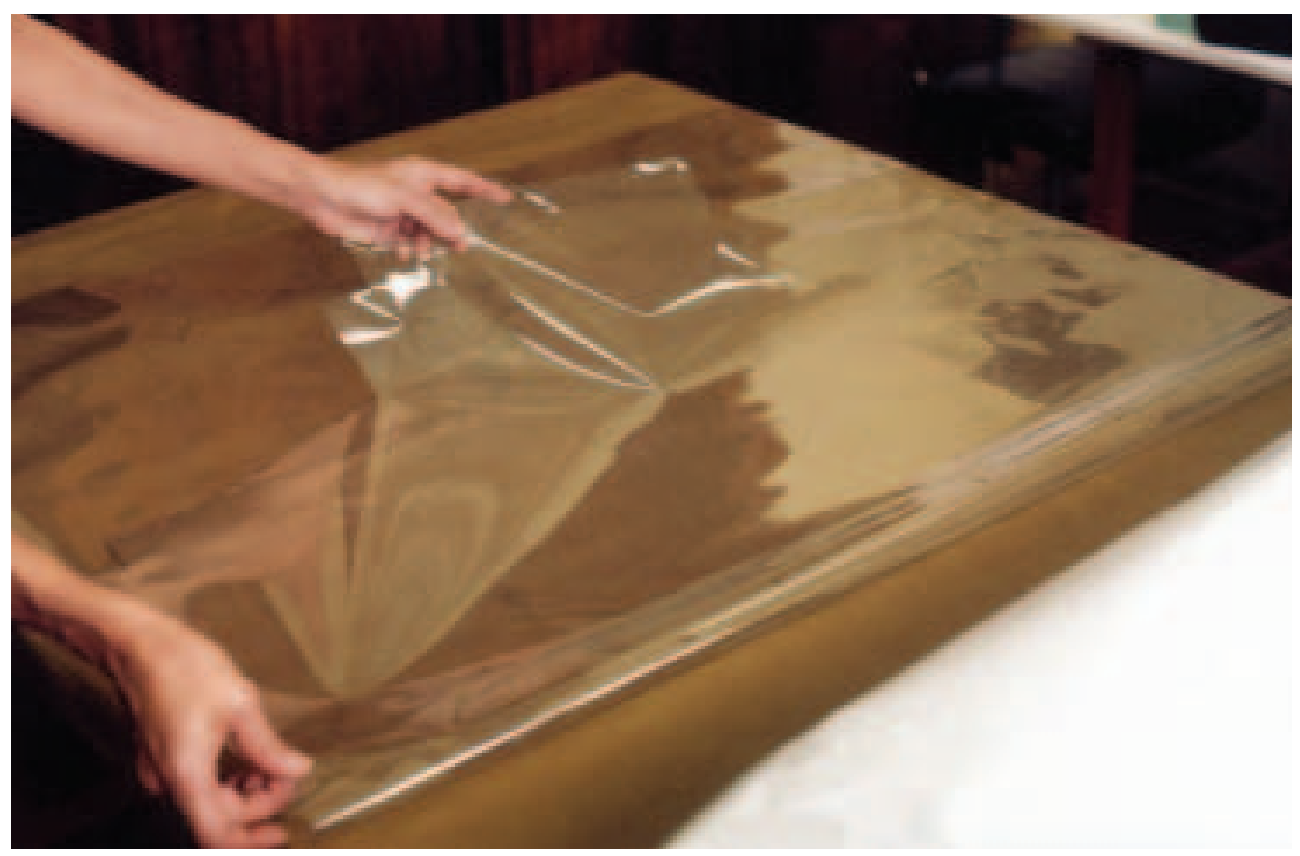

Figura 20 - Aplicação do tecido de microfibra de poliéster entre os tecidos do estandarte. 


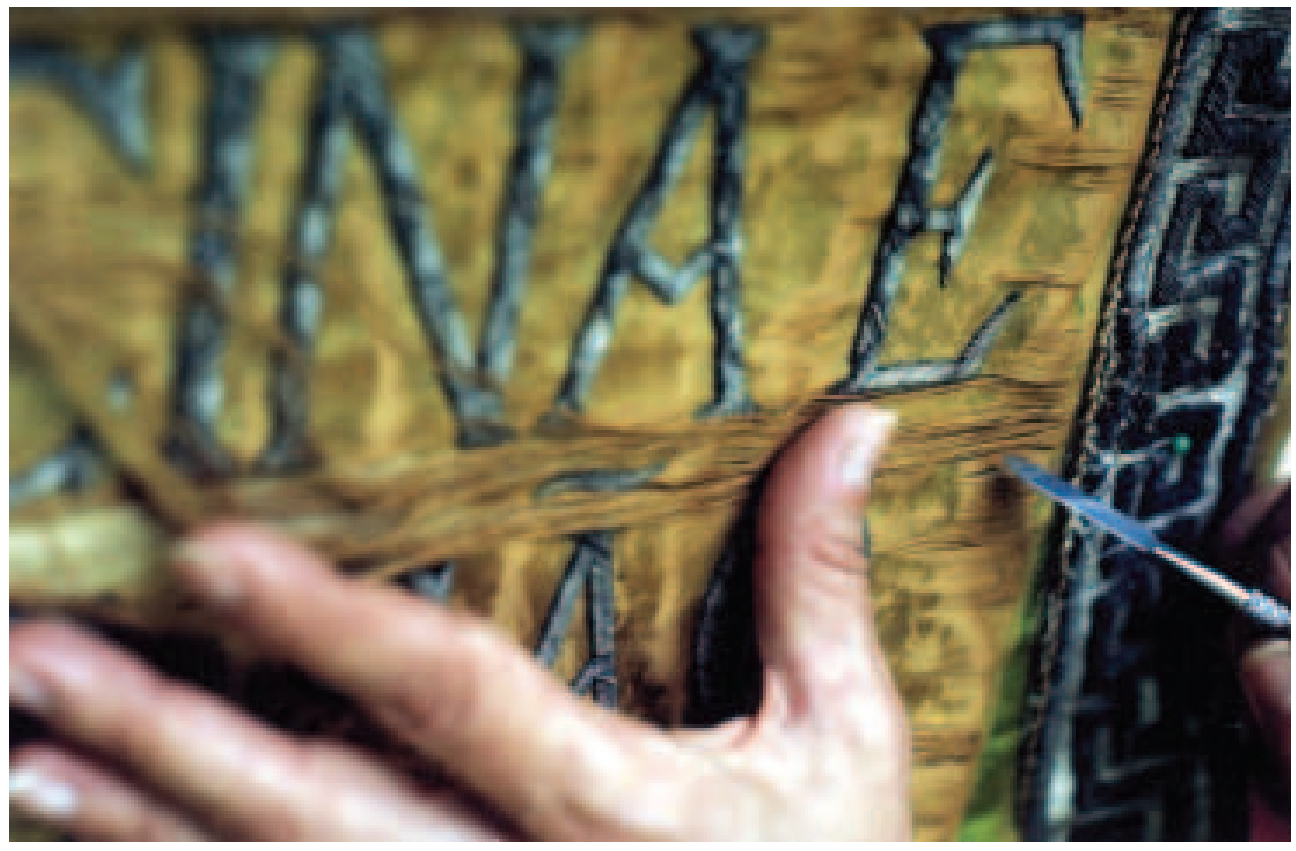

Figura 21 - Novo alinhamento, fio a fio, do tecido do anverso.

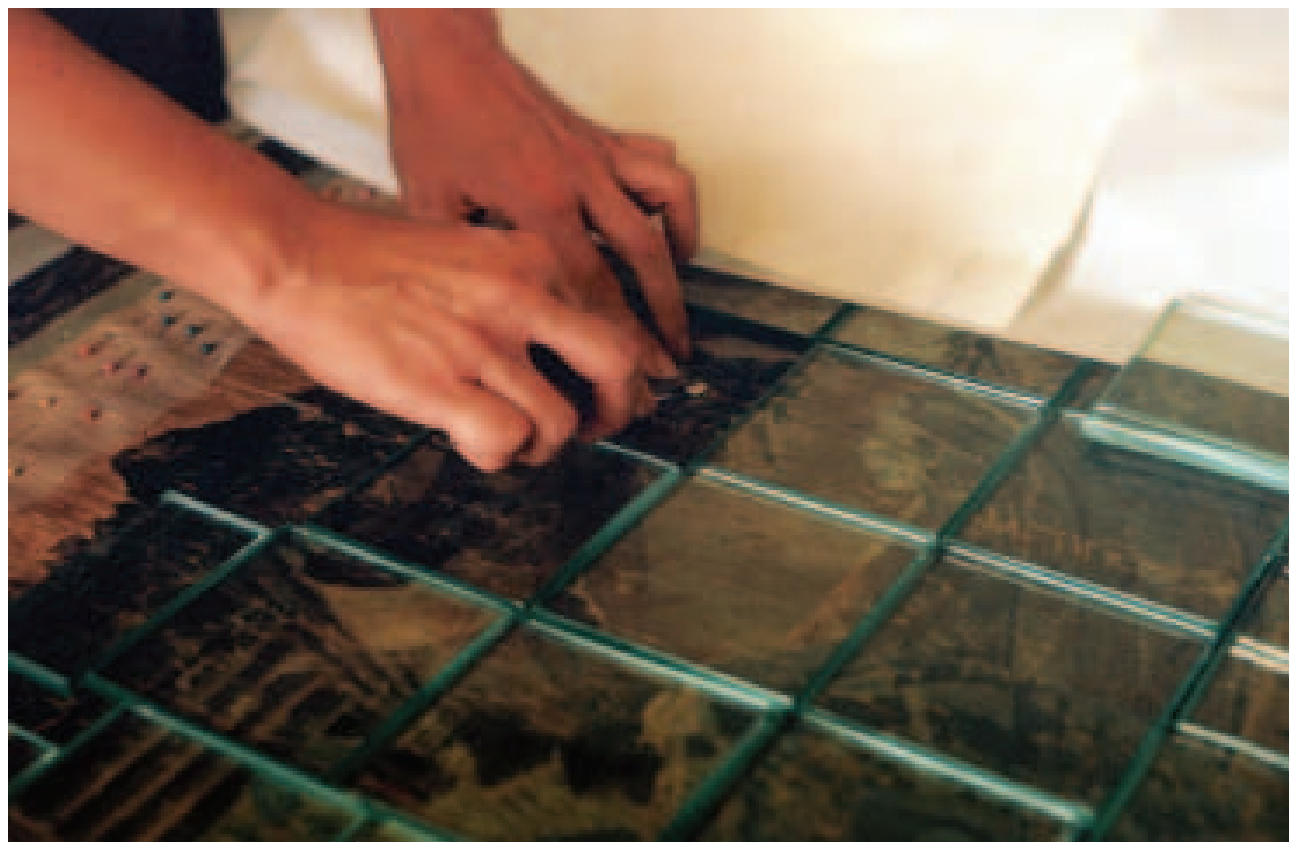

Figura 22 - Planificação da pintura com pesos de vidro. 


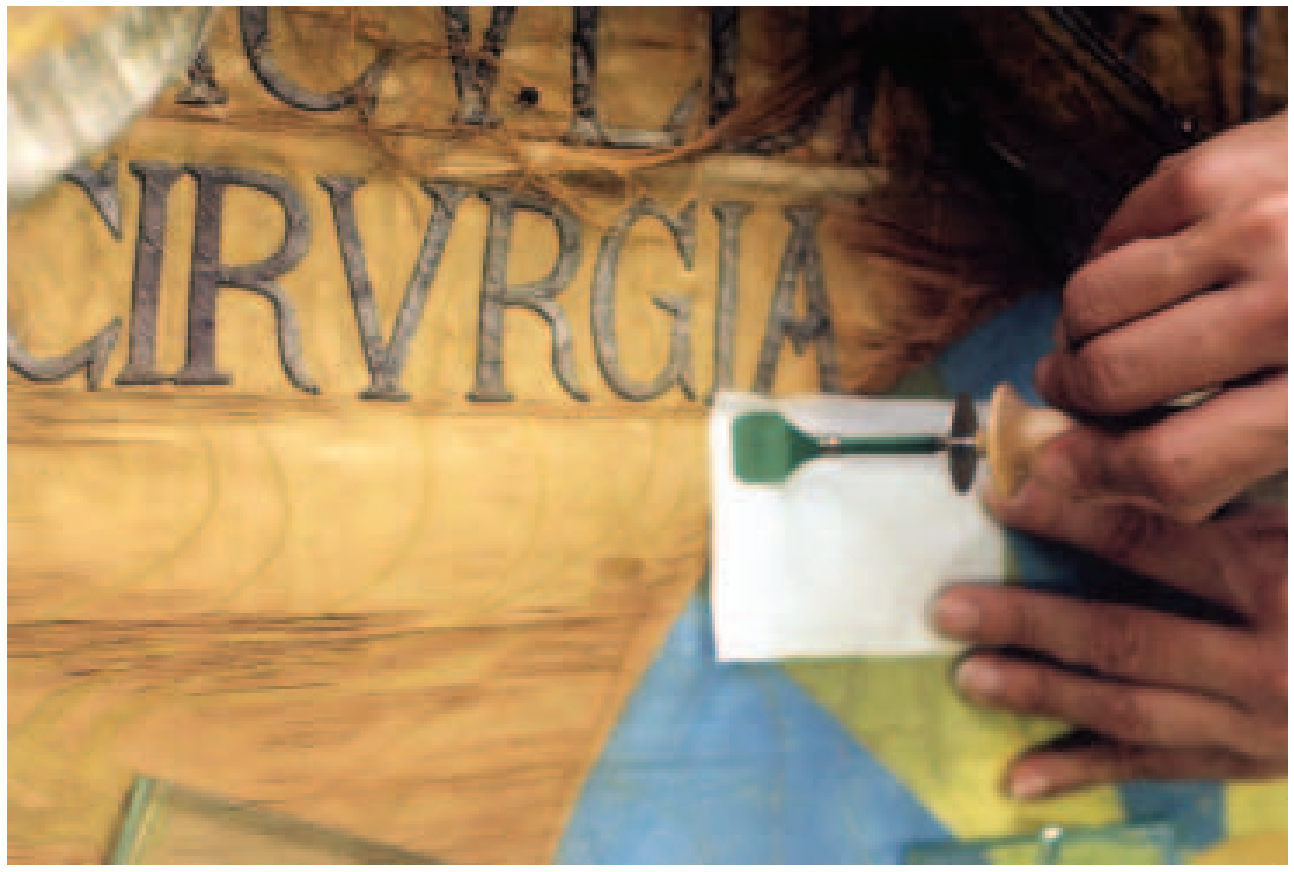

Figura 23 - Reativação do adesivo com espátula térmica sobre papel siliconado.

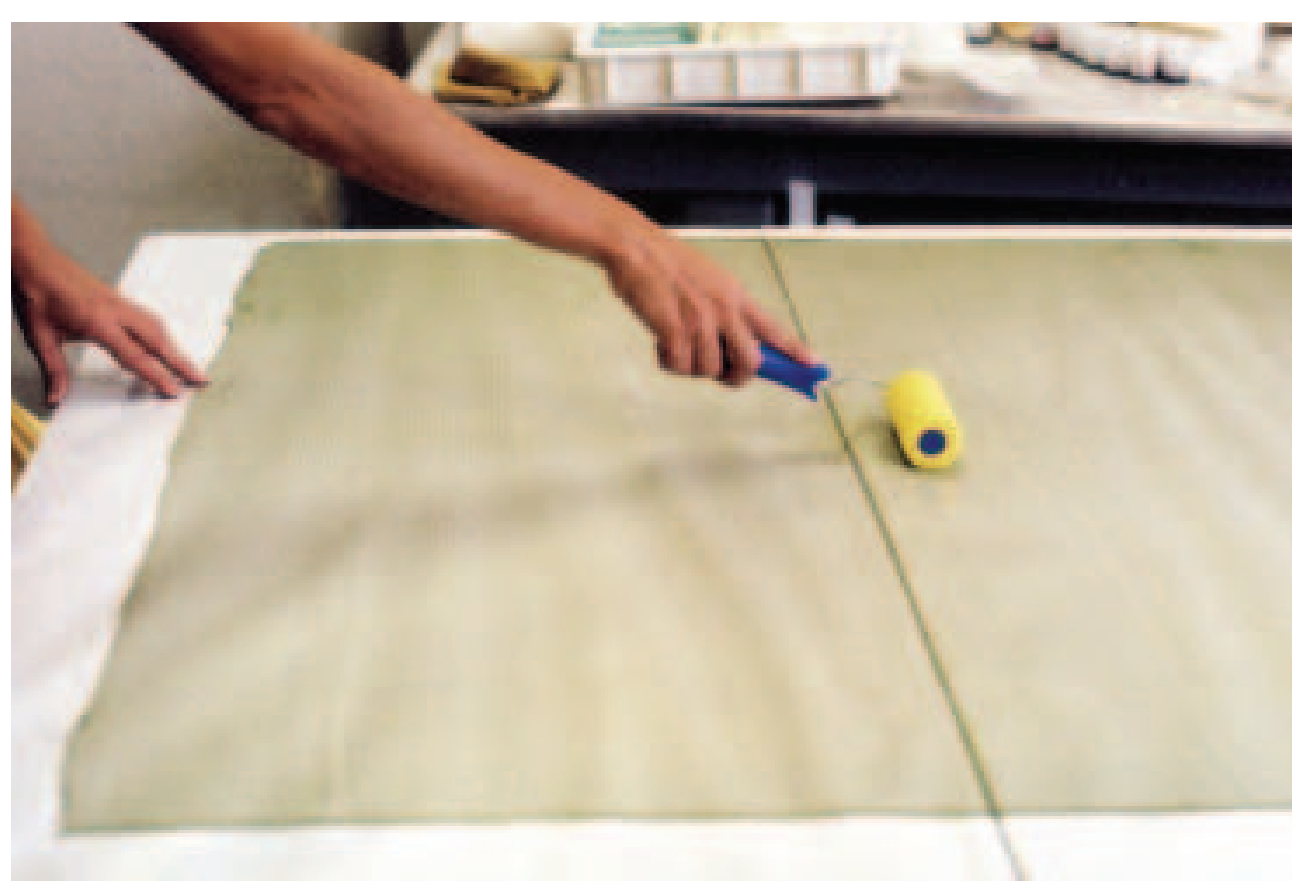

Figura 24 - Aplicação de adesivo sobre o tecido de crepeline de seda 


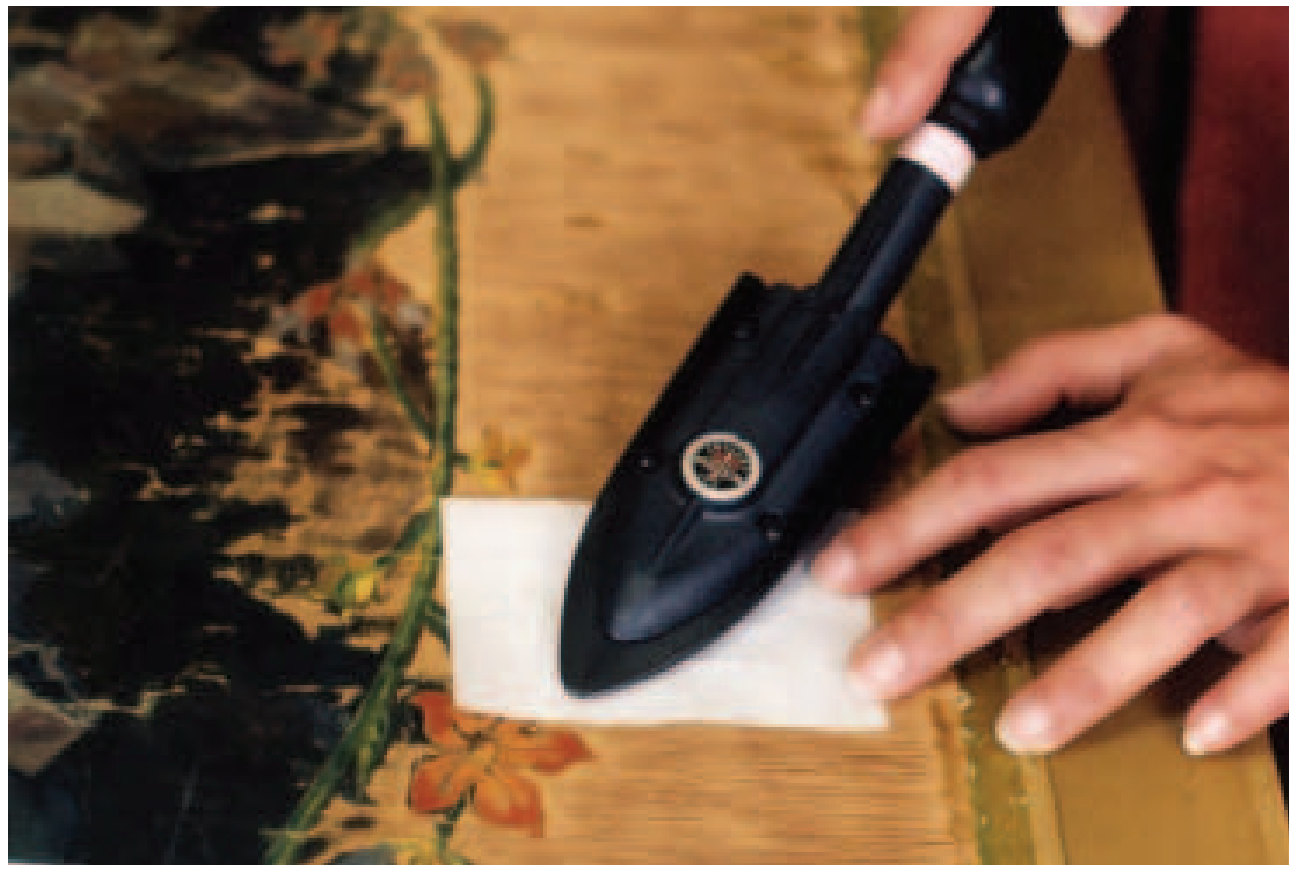

Figura 25 - Reativação do adesivo por calor.

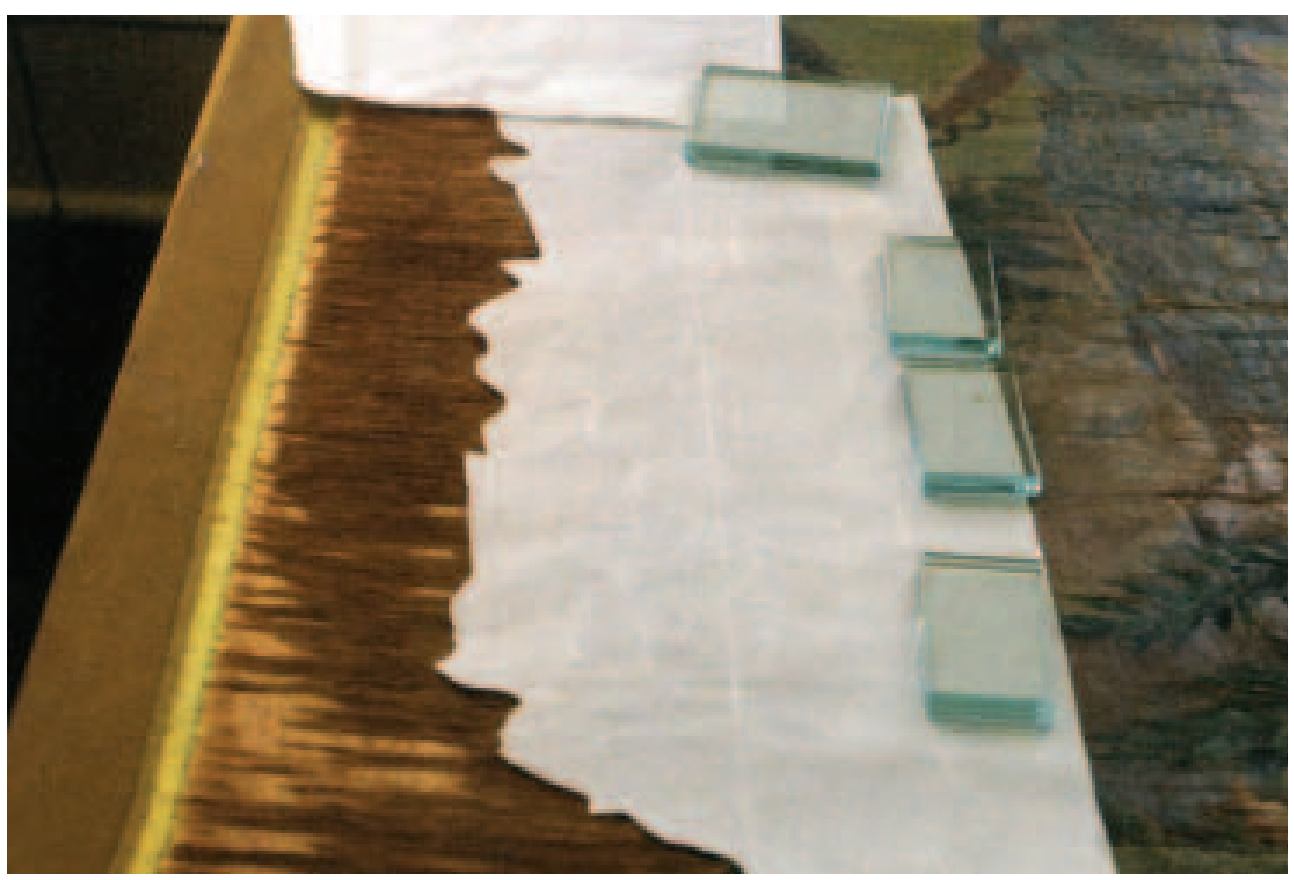

Figura 26 - Aplicação do tecido de crepeline de seda contornando a pintura. 


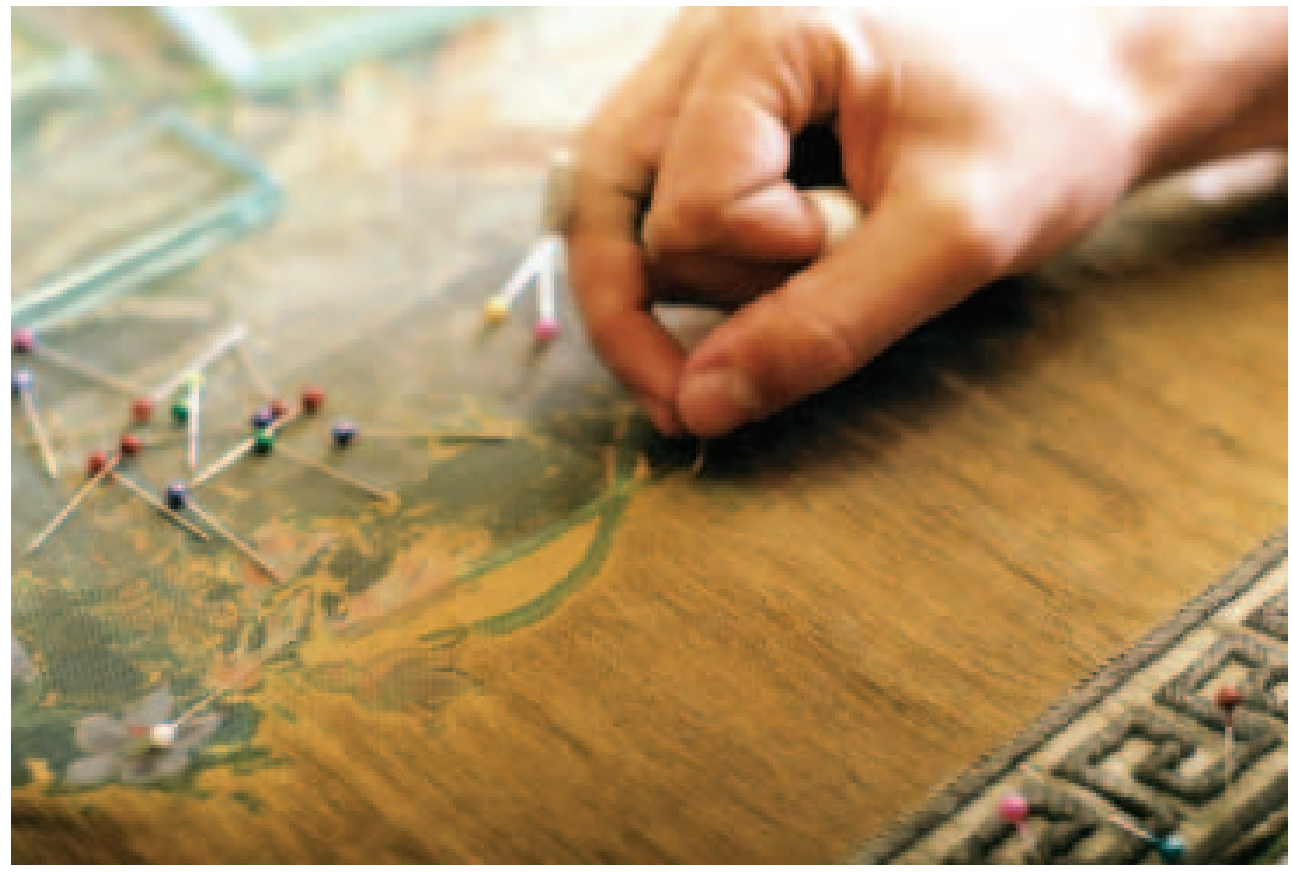

Figura 27 - Aplicação do tule, com costura, contornando a pintura.

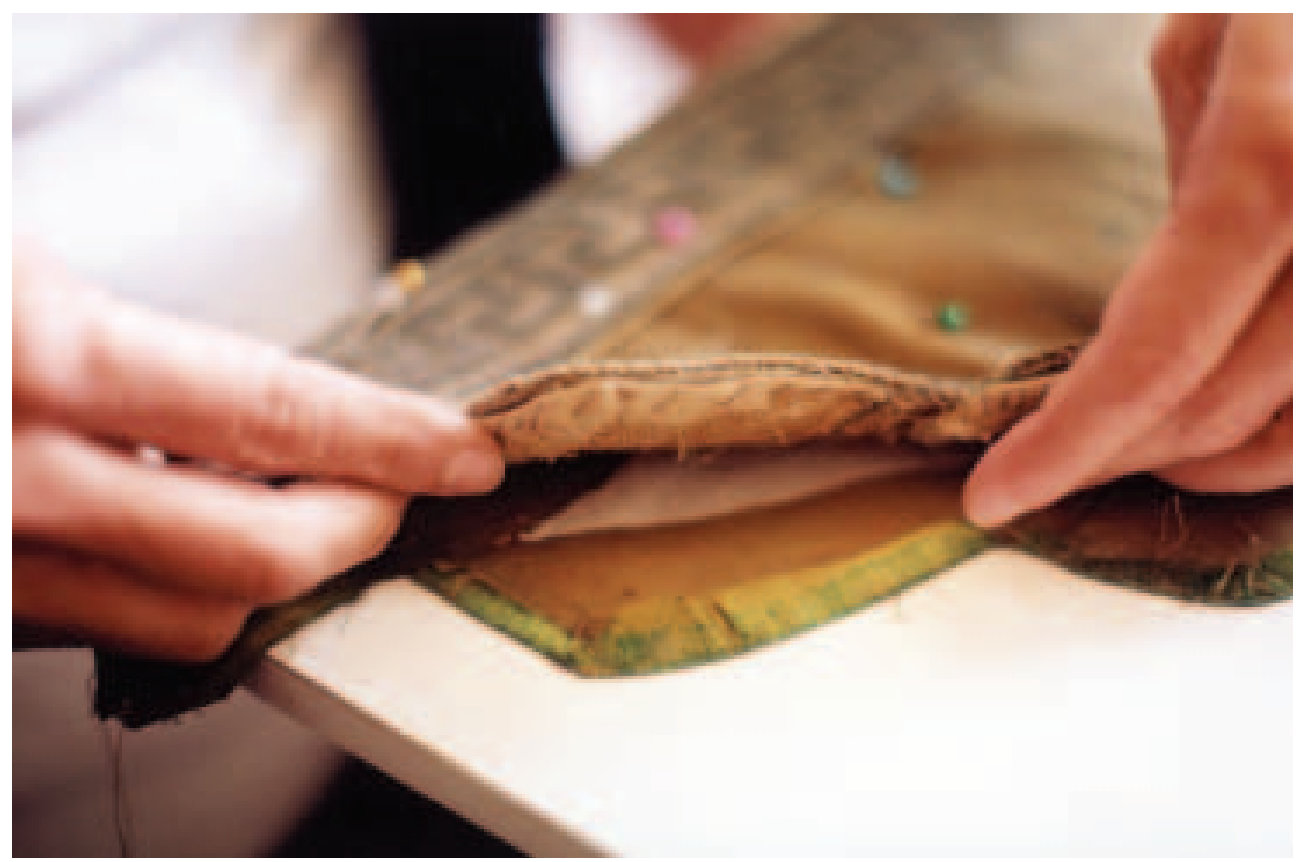

Figura 28 - Acomodação de todos os tecidos para as costuras finais de acabamento (detalhe). 


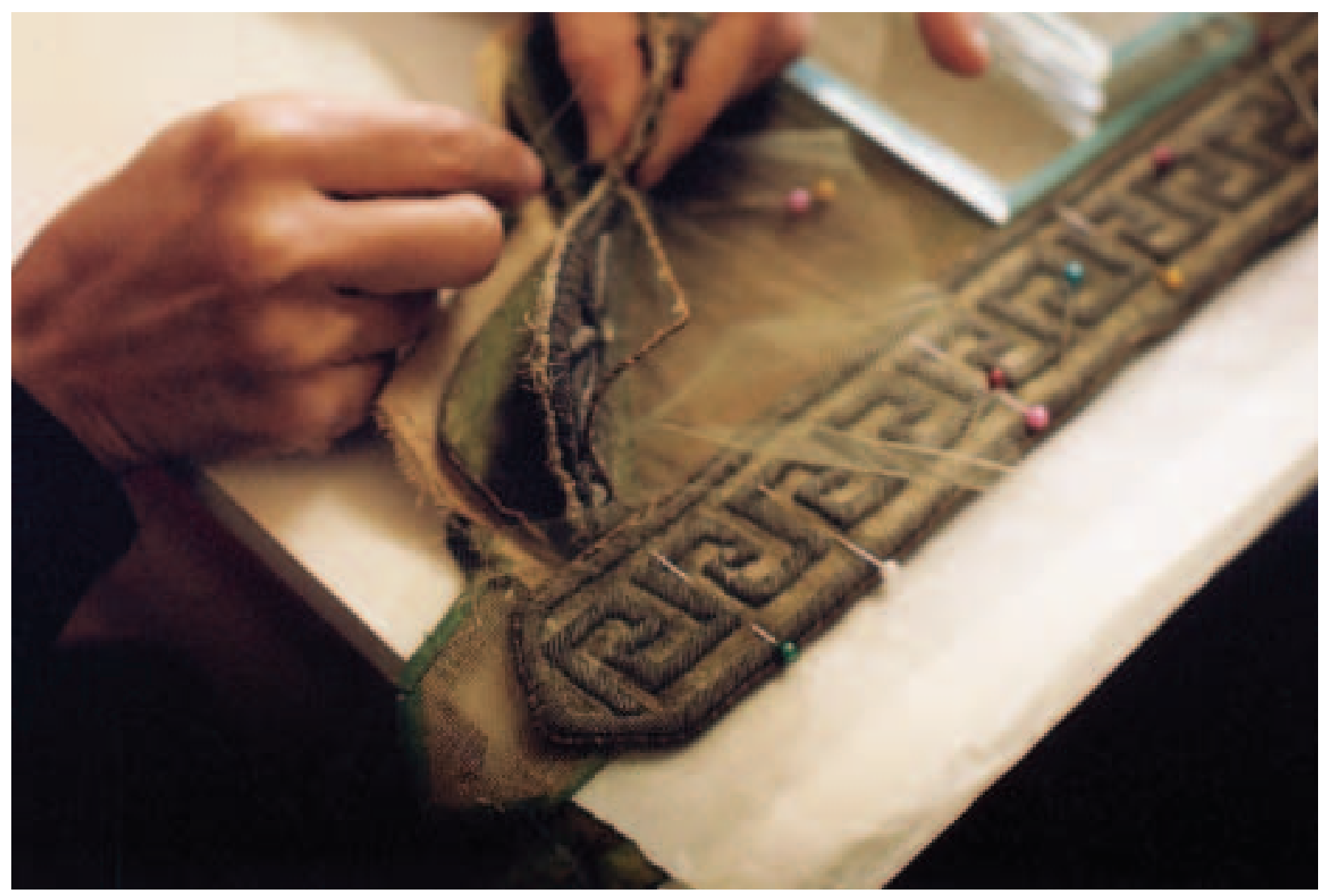

Figura 29 - Costura das partes, extremidade inferior direita (detalhe). 


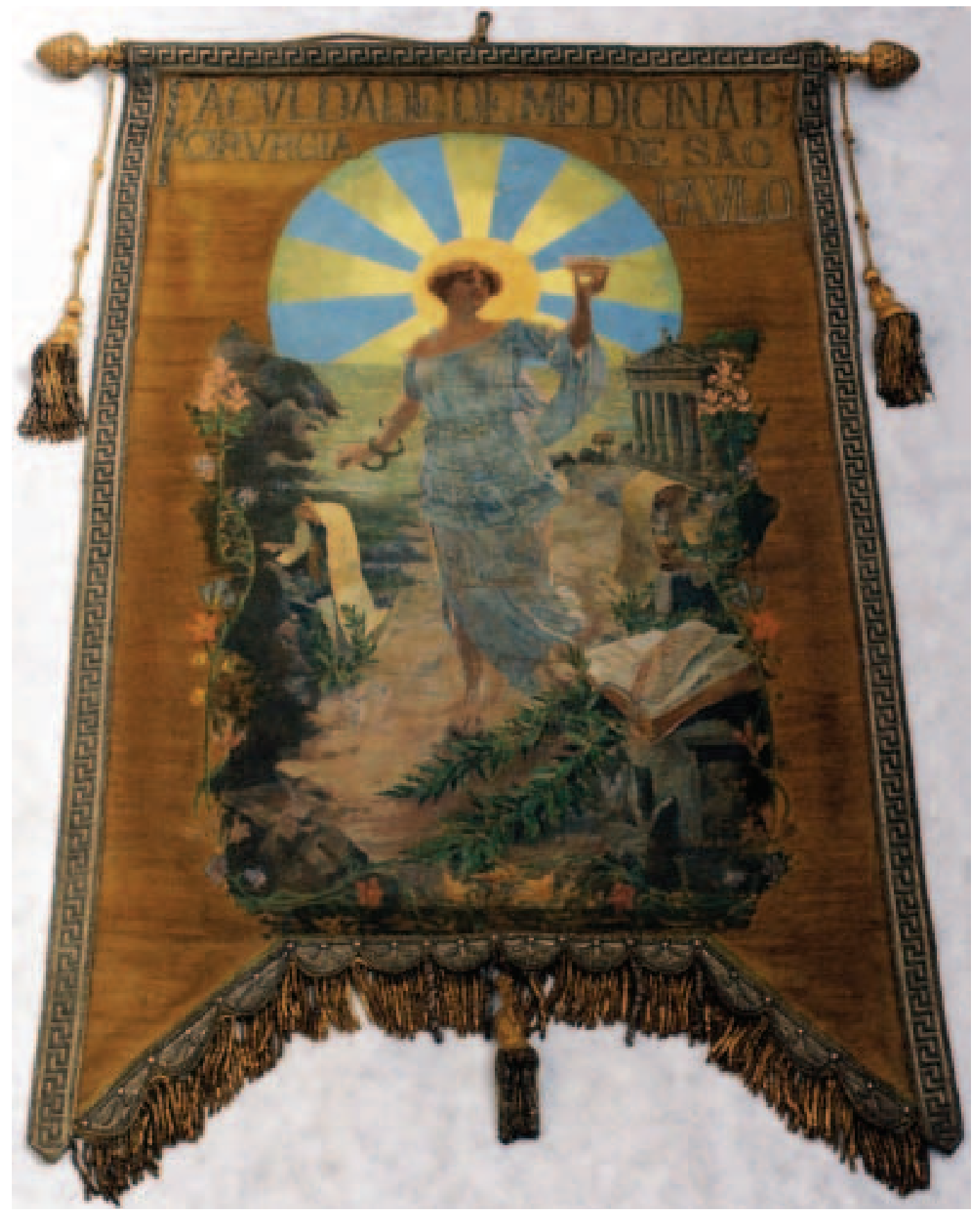

Figura 30 - Vista geral do estandarte - anverso - após a restauração. 


\section{REFERÊNCIAS}

BROOKS, M. M. Textiles Revealed. Object lessons in historic textile and costume research. London: Archetype, 2000.

GOHL, E. P. G;VILENSKY, L. D. Textile Science: an explanation of fibre properties. Melbourne: Longman Cheschire, 1983.

JOHANSEN, K. How to read historic textiles. In: BROOKS, M. M. Textiles Revealed. Object lessons in historic textile and costume research. London: Archetype, 2000, p. 53-66.

MAZZIERI, B. R. Símbolos na medicina. São Paulo: Museu Histórico da Faculdade de Medicina Professor Carlos da Silva Lacaz, 1995.

SMITH, L. M. When textiles are paintings. In: SYMPOSIUM 86 THE CARE AND PRSERVATION OF ETHNOLOGICAL MATERIALS. Proceedings... Otawa: Canadian Conservation Institute, 1986, p. 200-206.

TÍMAR-BALAZSY, A.; EASTOP, D. Chemical Principles of Textile Conservation. London: ButterworthHeinemann, 1998.

TRUPIN, D. L. Patriotism in fabric and Stitches: the history of flag conservation/restoration in the United States. In: ODDY,A.; SMITH, S. (Orgs.). Past Practice, Future Prospects. London: The British Museum, 2001, Occasional Paper 145, p. 189-194.

Artigo apresentado em 08/2004. Aprovado em 09/2004. 